\section{Intersections}

Canadian Journal of Music

Revue canadienne de musique
Intersections CANADIAN JOURAL OF MUSIC

\title{
The Theory and Practice of Integrating Invertible Counterpoint into Classical Theme-Types
}

\section{Peter Franck}

Volume 32, numéro 1-2, 2012

URI : https://id.erudit.org/iderudit/1018583ar

DOI : https://doi.org/10.7202/1018583ar

Aller au sommaire du numéro

\section{Éditeur(s)}

Canadian University Music Society / Société de musique des universités canadiennes

ISSN

1911-0146 (imprimé)

1918-512X (numérique)

Découvrir la revue

Citer cet article

Franck, P. (2012). The Theory and Practice of Integrating Invertible Counterpoint into Classical Theme-Types. Intersections, 32(1-2), 167-202. https://doi.org/10.7202/1018583ar
Résumé de l'article

Cet article examine l'utilisation du contrepoint réversible dans le cadre d'oeuvres thématiques conventionnelles de la tradition classique. Alors que de récentes recherches ont étudié comment cette technique contrapuntique peut créer une continuité, cet article contribue à cette question en montrant comment cette technique fonctionne de concert avec l'écriture thématique et les formes organisées par les cadences, et qui ont le propre d'interrompre la continuité. Un modèle de base sert de cadre théorique permettant l'analyse d'extraits tirés d'une sélection d'oeuvres de Haydn, Mozart et Beethoven. Les analyses montrent que certains types d'écriture thématique intègrent mieux que d'autres l'utilisation du contrepoint réversible dans leur organisation formelle. De plus, ces analyses mettent en lumière les divers rôles du contrepoint inversé dans les différentes formes thématiques.
Copyright ( C Canadian University Music Society / Société de musique des universités canadiennes, 2013
Ce document est protégé par la loi sur le droit d'auteur. L'utilisation des services d'Érudit (y compris la reproduction) est assujettie à sa politique d'utilisation que vous pouvez consulter en ligne.

https://apropos.erudit.org/fr/usagers/politique-dutilisation/ 


\title{
THE THEORY AND PRACTICE OF INTEGRATING INVERTIBLE COUNTERPOINT INTO CLASSICAL THEME-TYPES
}

\author{
Peter Franck
}

Within some Classical-style works, the technique of invertible counterpoint enables the simultaneous presentation of multiple melodies, or parts. ${ }^{1}$ In such a context, what was the lower part in one passage becomes the upper in a later one. Nowhere is such a technique more prevalent than in fugal writing, where fugal subjects are posited above and below accompanying counter-subjects. And within the Classical repertory, pride of place is given to the fugal finale, where the contrapuntal prowess of the composer is put to the test. ${ }^{2}$ But invertible counterpoint need not require fugal procedures for its use. Moreover, the application of invertible counterpoint, which can help to facilitate dialogue between different parts within a texture ${ }^{3}$-not only in symphonies, but also concertos, string quartets, and piano sonatas-is not restricted to final movements of works within the Classical repertory. Indeed, many non-fugal movements within this repertory contain theme-types that feature invertible counterpoint and can be comprehended using William E. Caplin's analytical approach to Classical form; 4 this methodology, however, does not explicitly address how invertible counterpoint interacts with musical form. The present essay thus explains not only technical aspects of this interaction, but also the purpose of integrating invertible counterpoint into Classical theme-types.

There are many non-fugal movements in the Classical repertory that employ invertible counterpoint as a sophisticated means of repetition. 5 For instance, in reference to the increased stylization of the minuet that took place over the course of the late eighteenth century, James Hepokoski and Warren Darcy write, "It became a musical genre subjected to the compositional craft of style-variation, something to be manipulated with wit and skill" (2006, 331). They continue, "Thus arose some subtypes of the minuet: the canonic, fugal, or otherwise "learn-

1 Following the practice of William E. Caplin, Classical style denotes the music of the high Viennese classical style, composed within the period ca. 1780-1810 (Caplin 1998, 3). Although some authors resist calling this music "Classical"-for instance, Robert O. Gjerdingen prefers "galant" $(2007,5-6)$, and James Webster dislikes this term, since it conflates meanings associated with time period, value, and style $(1991,348)$-this article employs Caplin's analytical methodology, thus referring to Classical style throughout is entirely appropriate.

2 See Brown 2003; Grier 2010; Horton 2006; and Kirkendale 1979, 56-57 and 141-48.

3 Keefe $2005,63$.

4 Caplin 1998.

5 In this regard, see Grier 2010, 76-82. 
ed' minuet (a display of compositional or contrapuntal ingenuity in the manner of a scholastic game)." Part of this "contrapuntal ingenuity" involves integrating invertible counterpoint into the context of conventional theme-types, such as the period or sentence. Although scholars generally agree that this is a "learned" practice, little research has been devoted to show how this practice interacts with the form of such theme-types. ${ }^{6}$ To be sure, James Grier convincingly demonstrates how Haydn summons invertible counterpoint within the finales of the op. 55/1 and op. 74/1 string quartets as a means of creating "rhythmically continuous passage[s] in which the voices constantly overlap without strong cadences and rhythmic articulations" (2010, 76). But the context he describes involves sections that normally express continuity, as in the development section of a sonata form (such is the case with the finale of op. 74/1), not a standard theme-type, which requires the systematic deployment of cadences-a means of quashing continuity-for its articulation. And although Simon P. Keefe keenly demonstrates how dialogue informs Mozart's late piano sonatas (2005, 63,67 ) - a practice arguably inherited from his concerto writing-apart from acknowledging the back-and-forth play between the right and left hands that some of these sonatas engender, little is said concerning the explicit use of invertible counterpoint and the specific theme-types through which this dialogue is expressed. Finally, despite the wealth of recent research concerning Classical form, little of it has been devoted to studying the concept of injecting invertible counterpoint into conventional eight-measure and sixteen-measure themetypes-a practice observed within many works of Beethoven, Haydn, and Mozart. Moreover, more needs to be investigated as to the function and purpose of invertible counterpoint within such contexts.

This essay addresses this lacuna of knowledge by initiating a study that shows how invertible counterpoint works in concert with these familiar themetypes. The essay contains four sections. The first section establishes a context in which to understand the use of invertible counterpoint within the Classical style. Here, I contrast the use of invertible counterpoint as it is commonly employed within Baroque practice to that within Classical practice, elucidating the kinds of parts contained within the invertible textures employed within the latter; additionally, I explain the purpose of using invertible counterpoint within Classical themes. The second section presents analytical models that encapsulate conditions by which theme-types using invertible counterpoint must abide; the models provide general templates with which to analyze specific examples. The next two sections provide analyses of excerpts of works by Beethoven, Haydn, and Mozart, which involve a variety of theme-types, including sentences, periods, hybrids, and compound themes, and combine the proposed models from the second section with Caplin's form-functional approach to thematic analysis $(1998,63-70)$. The third section focuses on themetypes involving two invertible parts, whereas the fourth section focuses on

6 Exceptions within current research include Caplin 2009, 103-11; and Schmalfeldt 2011, 48. Concerning "forms of the learned style," Leonard G. Ratner focuses on the use of canon, fugato, and fugue within Classical-style works (1980, 260-71); and Elaine R. Sisman expands the different meanings that the "learned style" can take (1996, 213-38). 
theme-types involving three or more invertible parts. Given the analyses, it becomes clear that theme-types containing only one cadence, such as the sentence, are more amenable to applications of invertible counterpoint than those that contain two or more cadences.

\section{InVERTIBLE COUNTER POINT WITHIN THE ClASSiCAL STYLE}

Invertible counterpoint entails switching the registral disposition of at least two musical parts such that lower parts can exchange registral positions with upper ones, and vice versa. Within such contexts, theorists, past and present, have emphasized the distinctness and autonomy that each part should convey. That is, each part is understood as independent from the others in that they project a distinct melodic contour and a unique rhythmic pattern. In this regard, Luigi Cherubini writes, "In double counterpoint the parts must be distinguished from one another as much as possible by the value of the notes" (1854, 51); Ebenezer Prout states that "the subject and counterpoint should be contrasted as much as possible, both in melody and rhythm" (1891, 58; italics original); and Kent Kennan explains that "there must be sufficient independence between the voices in terms of direction and rhythmic motion" $(1999,19)$. Related to the notion of distinctness is the view that each part should be autonomous and able to stand alone. For instance, according to Percy Goetschius, "Each line, sung or played alone, must produce a satisfactory melodic impression" (1910, 5); and for Kennan, "Each line must be good in itself" (1999, 19). Thus, according to the descriptions provided above, distinctness and autonomy are characteristics one would expect musical parts to convey when set in invertible counterpoint with each other.

Although these characteristics work well for describing musical parts as they occur within works in the Baroque style or in earlier styles, they work less well for later, more homophonic works, such as those within the Classical style. The earlier styles call to mind equal-voiced textures, whereas works in the Classical style often project textures consisting of primary (melodic) and secondary (accompanimental) parts. Despite this textural division of labour, invertible counterpoint still prevails within some Classical-style works. To this effect, Imogene Horsley, in the preface to her edition of Augustus Frederic Christopher Kollmann's An Essay on Practical Musical Composition, writes,

Scholars investigating the contrapuntal usages of the late eighteenth and nineteenth centuries have tended to stress their [composers'] use of fugue and canon, yet the most frequently used contrapuntal device in these times is invertible counterpoint. Mozart uses it constantly. Though Beethoven was slow at learning the conventions of fugue in his studies with Albrechtsberger, he mastered invertible counterpoint quickly and began using it right away in his compositions ... in fact, it is an ideal device for a style which stresses one predominant melody, since it makes possible the shifting about of the main melody and the component melodies of its accompaniment. (Kollmann 1799/1973, xxix) 
Despite her correct observation concerning the use of invertible counterpoint within the works of Beethoven and Mozart, she downplays its presence within Kollmann's works, largely for the simplicity of the secondary parts. Concerning a passage of quadruple counterpoint contained within a symphony of Kollmann's, she comments, "It shows the stylistic simplicity of much of the invertible counterpoint used in homophonic music and illustrates why this device is so seldom recognized - the secondary parts are so simple that one simply does not think of it as being contrapuntal, let alone being in invertible counterpoint. It is in sharp contrast to Baroque usage where there is a tendency to combine subjects of near equality. Here it is simply a practical device, not an exhibition of skill" (Kollmann 1799/1973, xxix).

Setting aside for now Horsley's ambivalence concerning the significance of invertible counterpoint within late eighteenth-century and early nineteenthcentury practice, she makes it clear that the music from this period includes textures consisting of primary and secondary musical parts, an observation confirmed by Kollmann himself and his contemporaries. For instance, he writes, "There is a great difference between the principal part or parts of a piece, and those called accompaniments; and even the latter must be divided into necessary and voluntary, or obligato [sic] and ad libitum ones." Concerning the obbligato parts, he writes, "Accompaniments of this sort may be set to a piece in two different manners, viz: first, so that the principal part and the accompaniment take the chief melody by turns, and form a sort of concertante" $(1799 / 1973,12) .^{7}$ The taking of turns here, of course, alludes to the practice of invertible counterpoint. Heinrich Christoph Koch also comments on such matters, especially as they pertain to the string quartet: "If it really is to consist of four obbligato voices of which none has priority over the others, then it must be treated according to fugal method. But because the modern quartets are composed in the galant style, there are four main voices which alternately predominate and sometimes this one, sometimes that one forms the customary bass" (Koch 1983, 207). Thus the sentiment expressed by Kollmann and Koch, here, is one of compromise: expression of invertible counterpoint, but one that factors in a hierarchy of musical parts.

In addition to the hierarchical role that musical parts often play within Classical-style textures involving invertible counterpoint, consideration should also be paid to the topical content that such textures project. In some cases, passages of invertible counterpoint within Classical works evoke the "learned style," such as through fugal practice, but in others, they can project a less elevated style, such as through non-fugal, motivic imitation, and fall under the category of what Elaine R. Sisman describes as "Classical counterpoint" (1996, $218-21) .{ }^{8}$ In a comparison of the two styles, learned style typically projects a

7 The second manner involves the accompaniment serving only as a bass or inner voice. Additionally, Kollmann is referring to instrumental parts, not voices in the music-theoretic sense.

8 "Learned style," a topic in the music-semiotic sense, connotes the employment of contrapuntal techniques, such as imitation, fugue, and canon. The notion of learned style originates in the research of Leonard Ratner (1980) and has been expanded further in Agawu 1991; Allanbrook 1983; Balter 2012; Hatten 1994; Monelle 2006; Sisman 1996; Somfai 1986; and Somfai and Ausser 1988. 
serious ethos, typical of sacred music, whereas Classical counterpoint conveys a much more "secular" one, as would be found within a minuet. ${ }^{9}$ Summoning counterpoint in these two ways loosely corresponds to the aforementioned types of musical parts one would expect to find in contrapuntal textures within Classical works: learned style involves parts contained within an equal-voiced context, as found within sacred, vocal polyphony, but Classical counterpoint (often, but not always) involves a hierarchical arrangement of parts that are instrumentally oriented. The former style involves parts that one would construe as melodies, typically to be sung, whereas the latter style often employs parts specifically tailored for and/or evocative of instrumental reproduction, as suggested by such topics as brilliant style, Alberti bass, or hunt style. ${ }^{10}$ Regardless of which type of texture a passage may project-learned style or Classical counterpoint-both types are capable of containing musical parts set in invertible counterpoint. (The large majority of works presented in this essay fall into the Classical counterpoint category.) Thus the topical content of a passage does not bear on the invertibility of its constituent musical parts, but rather on the characteristic qualities of the musical parts themselves.

In Classical-style contexts, therefore, since musical parts can play different roles (primary, secondary, principal, accompanimental, etc.) and be combined into textures that are either "learned" or Classical in orientation, we need to expand our notion of what are viable musical constituents within the passages of invertible counterpoint that we explore. Thus, referring to each part as a "melody" is not entirely representative (though in some cases this might be appropriate), since some parts exhibit a lower melodic profile than others. Additionally, research into the psychology of hearing demonstrates that listeners organize musical phenomena into discrete perceptual units known as streams. ${ }^{11}$ Listeners differentiate between different streams according to preferences for a variety of factors, including stepwise motion, avoidance of synchronous onsets, use of different rhythms, avoidance of voice-crossing, timbral contrast, avoidance of parallel motion, tempo/consecutive melodic-interval combinations suggesting multiple voices (polyphonic melody), and even spatial separation amongst performers within a concert setting. ${ }^{12}$ The fallout from these preferences is that listeners group musical phenomena, not necessarily into different "melodies" or "voices" in the conventional music-theoretic sense, but rather into more generally defined "chunks" or streams that occupy low, middle, and upper registers of a texture. Thus, because there is a variety of ways that musical parts put into invertible passages can be set and/or perceived, I will refer to each recognizable constituent that participates within such passages as simply

9 Agawu mentions the notion of "secular" counterpoint, an expression coined by Giorgio Pestelli (Agawu 1991, 31).

10 See ibid., 30, for a fuller list of topics.

11 Streams fall under the purview of auditory stream segregation and auditory scene analysis, concepts associated largely with the pioneering research of Albert S. Bregman (1990). There is a wide body of literature concerning this research area, a small sample from which are Bey and McAdams 2003; Cambouropoulos 2008; Deike et al. 2004; Deutsch 2010; and Pressnitzer et al. 2011.

12 Bey and McAdams 2003, 274; Bregman 1990, 496-502; Deutsch 2010, 42; Pressnitzer et al. 2011, 3-4. 
a part. Parts, therefore, can take on many different guises: distinct melodies, doubled melodies in thirds or sixths, Alberti basses, chordal accompaniment, and even pedals. Additionally, when parts exchange positions with each other, they sometimes undergo subtle changes once in their new inverted context; despite these changes, we can still regard the inverted passage as a case of invertible counterpoint. In this sense, we, as listeners, would be responding more to the rhetoric of invertible counterpoint, rather than the precise path that each part follows. Although I am levelling the playing field concerning labelling the myriad types of parts that can enter into an invertible context, this simply provides an initial stage of analysis; once the constituent parts have been identified, we can then explore the different roles and characters they play and exhibit.

Finally, we must address, if only provisionally, the rationale of setting such parts in invertible counterpoint within the context of a Classical theme. One possible purpose would be to provide a means of varied repetition. Repetition is a primary feature of all the themes we will discuss; indeed, it is a primary feature of music, in general (Huron 2006, 228-31). For instance, a consequent phrase is generally understood as a varied repetition of an antecedent phrase, with variation coming by way of the unique cadences that close and distinguish the one phrase from the other. Similarly, in other formal contexts, varied repetition can result, though not necessarily so, through the application of invertible counterpoint. Indeed, in recent literature on the first movement of Beethoven's Tempest sonata (Caplin 2009, 103-11; and Schmalfeldt 2011, 48), some of the reasons proposed for the use of invertible counterpoint include summoning different formal functions, inhibiting or modifying cadential articulation, and obscuring formal boundaries. To this we add other reasons, such as forestalling monotony within passages containing-or between passages that undergo-numerous repetitions (Huron 2006, 367), and delineating musical patterns by making contiguous events containing the same material more noticeably separable, or distinct (Meyer 1973, 83). On the face of it, eliminating monotonous musical passages may seem to be rather trivial; but upon further consideration, it allows more repetitions within a passage to occur-a means of formal expansion-than would normally be the case. Thus relieving monotony via invertible counterpoint becomes not just an end in itself, but also a formal strategy.

\section{BASIC MODEL OF INVERTIBLE COUNTERPOINT WITHIN THEME-TYPES}

The practice of applying invertible counterpoint within theme-types is highly constrained by the cadences that help to articulate their form. Consider example 1 , which rewrites the opening theme from Mozart's Piano Sonata in $\mathrm{B}^{b}$ Major, K. 333, iii. Measures 1-4 show Mozart's original music (though the end of $\mathrm{m} .4$ is altered), whereby the soprano is labelled $x$ and the bass $y$; and $\mathrm{mm}$. 5-8 contain my rewriting of the first four measures by inverting both parts such that part $y$ now appears above part $x$. Although the entire theme gives the 


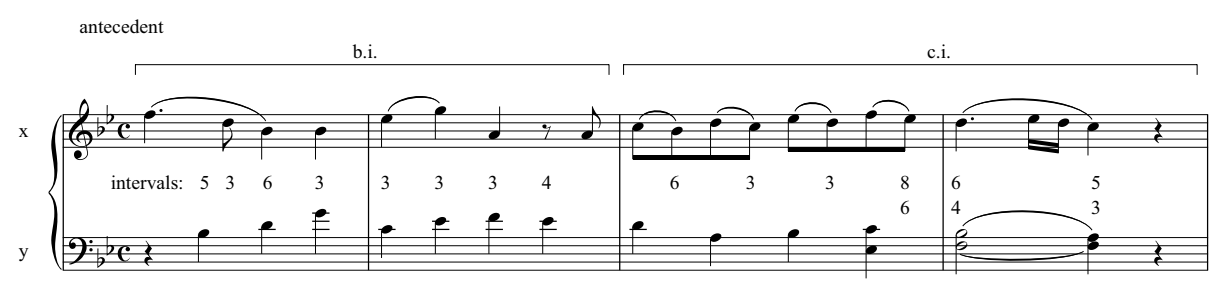

B::

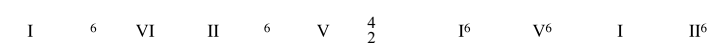

$\mathrm{v}_{4}^{6} \varlimsup_{3}^{5}$

$\mathrm{HC}$

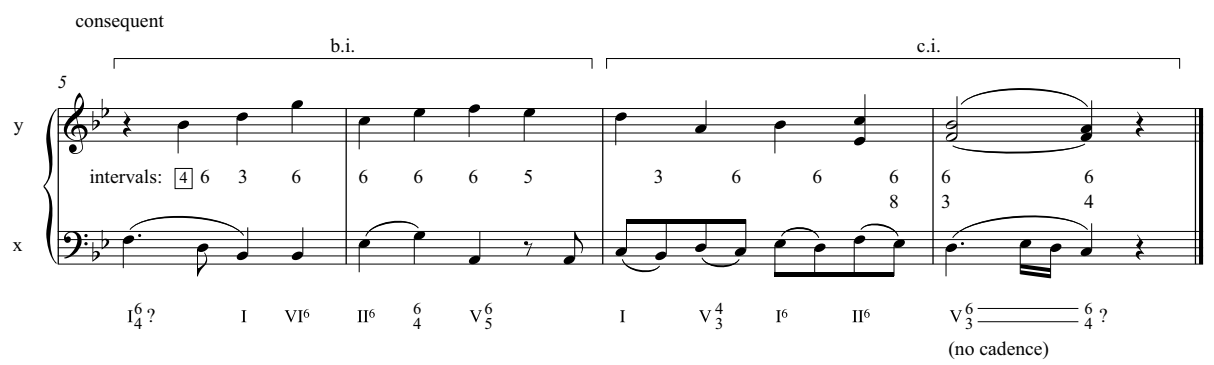

Example 1. Rewritten version of theme from Mozart, Piano Sonata in Bb Major, K. 333, iii

(a) Basic model

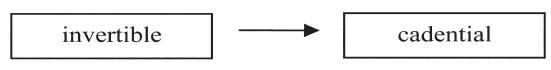

(b) Variant of basic model with additional transitional zone

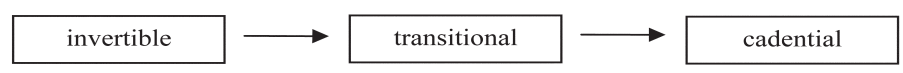

Figure 1. Basic model of formal units that include cadences and invertible counterpoint

outward appearance of being in period form, the lack of a cadence and tonic harmony in m. 8 renders the theme incomplete. (Moreover, the perfect fifth separating both parts at the outset of the antecedent inverts into a dissonant fourth at the beginning of the consequent.) Thus my recomposition demonstrates that integrating invertible counterpoint into theme-types involves more than just upending parts one over the other; indeed, it shows that a compromise must be made between registrally exchanging parts, on the one hand, and articulating cadences, on the other. 
We can encapsulate such a compromise in the form of a basic model (figure 1). At (a), the basic model maps out two zones that generally prevail in any complete formal unit (such as a presentation or antecedent) that incorporates invertible counterpoint: invertible and cadential. ${ }^{13}$ The invertible zone refers to an area where parts that are intended to invert with each other may appear above or below each other. The cadential zone demarcates the space in which the cadence occurs, thus closing off any possibility for invertible counterpoint to prevail. A variant of the basic model, shown at (b), inherits the two zones from the one at (a) but also includes a transitional zone that separates the invertible from cadential zones. This additional zone contains neither invertible nor cadential content. The invertible zone (in either version of the model) can start at the very beginning of a theme, such as in a presentation of a sentence, or it can begin midstream, such as in a continuation. ${ }^{14}$ Additionally, sometimes an invertible zone will gradually diminish as a theme progresses towards the transitional or cadential zone. Such a scenario occurs when, after parts have inverted positions with each other and the music gets closer to the end of the invertible zone, at least one of the parts starts to undergo changes sufficient to render it as being altered from its earlier appearance in its original registral position. Similarly, this situation can also work in reverse, where the invertible zone gradually comes into being near the beginning of a formal unit containing an inverted repetition of an earlier passage (as could happen within a consequent phrase) due to changes evinced by one of the parts participating within the inversion.

The two versions of the basic model shown in figure 1 may be simple and abstract, but this allows us to make the following inference: theme-types with fewer cadences permit more opportunities for invertible counterpoint to flourish..$^{15}$ For instance, a sentence is more likely to include invertible counterpoint than a period, since the former theme-type contains only one cadence and the latter two. On the basis of this notion, we can create a table of theme-types listing the number of cadences they contain (table 1). ${ }^{16}$

13 Although zones are employed within sonata theory (Hepokoski and Darcy 2006), their use throughout this article is not meant to deliberately reference that theory nor detract from Caplin's. Rather, zones here demarcate spaces within which particular formal functions may reside.

14 A continuation-a shortened form of continuation phrase-is the second of two phrases within a sentence that combines continuation and cadential functions. According to Caplin, "Continuation function destabilizes the prevailing phrase-structural, rhythmic, and harmonic context (as defined by the presentation) and features a breaking down of the structural units (fragmentation), an increase in rhythmic activity (acceleration of harmonic change and shorter surface durations), and a weakening of harmonic functionality (sequential progression). Cadential function brings closure to the theme and is characterized by tonal confirmation (cadential progression) and the conversion of characteristic motives into conventional ones (liquidation)" (1998, 40).

15 See Grier 2010, 76 (cited above), which comments on the lack of cadences within passages involving invertible counterpoint.

16 The table excludes rounded binary, since this form would already have embedded within it the theme-types currently listed in the table. Although Caplin prefers small ternary to rounded binary $(1998,71-73)$, he states that they "must be understood, nonetheless, as essentially the same form." I have chosen to use rounded binary throughout because this expression is more familiar. 
Table 1. Number of cadences within eight-measure and sixteen-measure theme-types

\begin{tabular}{|c|c|c|c|}
\hline Theme-type & 1 cadence & 2 cadences & 4 cadences \\
\hline Sentence & $x$ & & \\
\hline Period & & $x$ & \\
\hline Hybrid 1 (antecedent + continuation) & & $x$ & \\
\hline Hybrid 2 (antecedent + cadential) & & $x$ & \\
\hline Hybrid 3 (c.b.i.. + continuation) & $x$ & & \\
\hline Hybrid 4 (c.b.i. + consequent) & $x$ & & \\
\hline $\begin{array}{l}\text { Sixteen-measure period (presentation + } \\
\text { continuation) } \dagger\end{array}$ & & $x$ & \\
\hline $\begin{array}{l}\text { Sixteen-measure period (c.b.i. + } \\
\text { continuation) }\end{array}$ & & $x$ & \\
\hline $\begin{array}{l}\text { Sixteen-measure period (antecedent + } \\
\text { continuation) }\end{array}$ & & & $x$ \\
\hline Sixteen-measure sentence & $x$ & & \\
\hline
\end{tabular}

The theme-types with only one cadence represent the most likely choices for employing invertible counterpoint, those with two cadences less likely, and those with four the least. One caveat must be made concerning the sixteenmeasure periods containing presentation or compound basic idea (c.b.i.) within their eight-measure antecedents and consequents; since both these eight-measure units contain only one cadence, the larger periods of which they are a part are also some of the more likely candidates to contain invertible counterpoint within their confines. Equipped with the basic model and our understanding of which theme-types are more likely to contain invertible counterpoint than others, we will now investigate relevant examples from the literature.

\section{ANALYSES OF PIECES INVOLVING TWO INVERTIBLE PARTS}

We begin by looking at a sentence from Mozart's Piano Sonata in C Major, K. 545, i (example 2). The focus here is the continuation, which undergoes a varied repetition through the application of invertible counterpoint. Concerning the analysis, form-functional labels occupy the layer directly above the staff, whereas the labels relating to the basic model, abbreviated and presented in capital letters, occupy the top layer. As shown, the invertible zone consists of the continuation and its repetition; the cadential zone covers the last four measures of the theme, where no invertible content obtains.

The overall purpose of using invertible counterpoint within the theme is to avoid monotony, expand the form, and clearly demarcate a modulation from the subdominant to the tonic key. Here, brilliant passage-work that first appears in the upper register (part $x$ ), starting in $\mathrm{m} .46$, moves to the lower register in m. 50. Meanwhile, this passage-work is accompanied (mostly) by chords (part $y$ ) that first appear beneath and then above part $x$. The passage-work takes on the primary role while the accompanying chords take on a secondary 


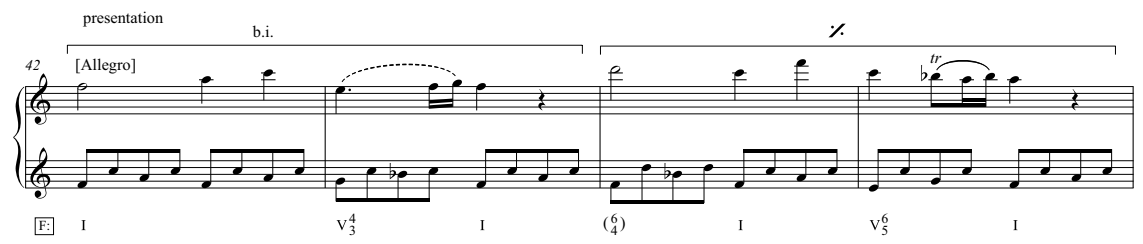

INVERT

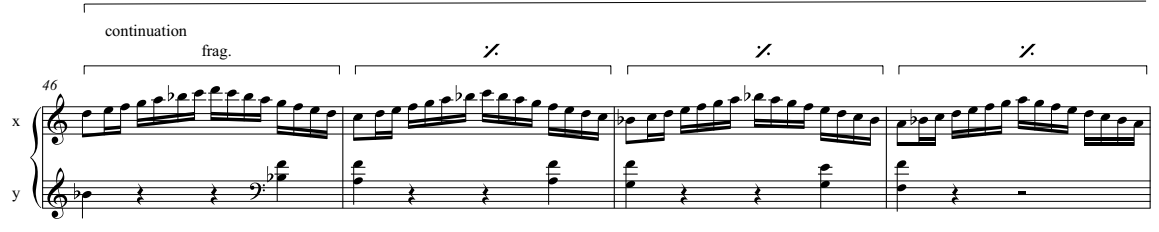

IV

$I^{6}$

$\mathrm{VII}^{7}{ }^{6} \quad \mathrm{I}$

INVERT, contd.

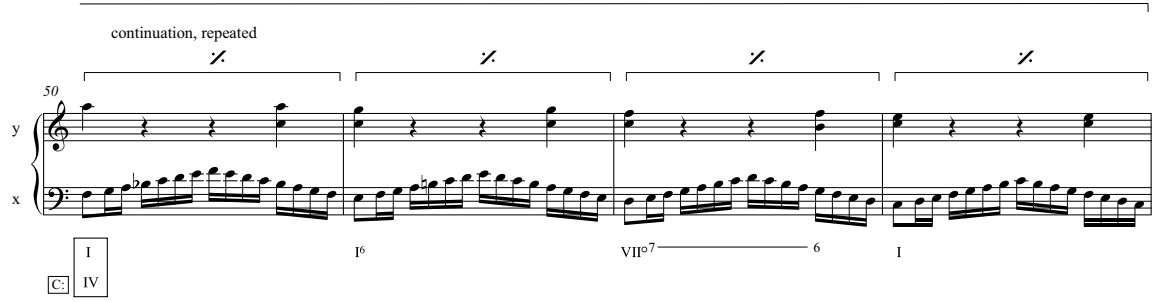

CAD

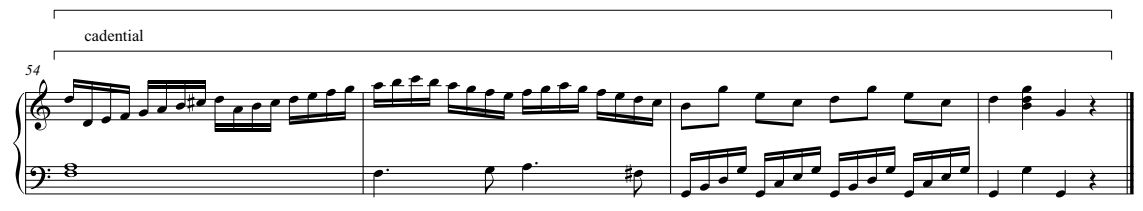

$\mathrm{II}^{6}$

IV $^{6} \quad \mathrm{~V}_{5}^{6} / \mathrm{V} \quad \mathrm{V}$

$\mathrm{HC}$

Example 2. Analysis of Mozart, Piano Sonata in C Major, K. 545, i, mm. 42-57

one. The switching of parts precludes tedium from setting in by preventing the eight-fold scalar run contained in part $x$ from appearing in the right hand only. Additionally, invertible counterpoint expands the dimensions of the continuation phrase here within the recapitulatory main theme from that within its expositional counterpart, intensifying the drive to the half cadence that closes the theme. ${ }^{17}$ Moreover, the expansion provides room in which to modulate back to the home key.

Specifically, with formal space now allocated, the inversion of parts serves to highlight the return to the home key within this sonata-form movement. The recapitulatory main theme in which these parts are placed occurs within the unconventional non-tonic key of F major, IV; a modulation to the home

17 The expansion could fall under the rubric of "additional model-sequence technique," one method of altering recapitulatory main themes and transitions. See Caplin 1998, 163-65. 
key, however, evinces itself by the end of the theme in the form of a I:HC. ${ }^{18}$ The modulation itself involves the inversion of parts $x$ and $y$ within the continuation. In the first four measures of the continuation, both parts create outervoice parallel tenths and articulate the harmonic progression $\mathrm{IV}-\mathrm{I}^{6}-\mathrm{VII}{ }^{\circ 6}-\mathrm{I}$ in F major; in the next four measures (mm. 50-53), the parts switch hands but still articulate the outer-voice tenths and the same harmonic progression, though this time in $\mathrm{C}$ major. The nature of the inversion here involves invertible counterpoint at the twelfth, which enables outer-voice thirds (or tenths) articulated by $x$ over $y$ to invert to tenths when both parts exchange positions with each other. Because the outer-voice counterpoint is preserved, Mozart is able to maintain the same harmonic progression from the one passage to the next, despite the inversion of parts. In contrast to this invariance, the inversion of parts helps to dramatize the modulation back to $\mathrm{C}$ major. Thus in this sense, inversion helps to articulate form, pointing up the return to the home key within the recapitulatory main theme through an explicit change in texture. More subtly, it also smoothes out the seam that connects both keys. That is, had there been no inversion, the transition from m. 49 (the last measure of the continuation) to m. 50 (the first measure of its repetition) would sound repetitive, static, and somewhat clunky, for lack of harmonic progression and virtually no change in melodic design. Thus the inversion imparts a sense of motion, not only of parts $x$ and $y$ moving to opposite hands, but also that between keys.

The reasons for using invertible counterpoint within Mozart's Rondo in $\mathrm{F}$ Major, K. 494, minore, are somewhat different from those supporting its use in K. 545. Shown in example 3, invertible counterpoint summons different formal functions and inhibits cadential articulation with the repetition of previously heard material. The upper and inner voices are labelled as $x$ and $y$, respectively, at (a), and invert positions with each other later within the minore (shown at [b]), which is in rounded binary form. ${ }^{19}$ In both themes, parts $x$ and $y$ are clearly on an equal footing-neither plays a secondary role-since much of their respective melodic content is structurally identical, though presented canonically and under transposition. As shown at (a), the first four measures articulate an antecedent phrase, concluding with a I:IAC. ${ }^{20}$ After the cadence in m. 98, a continuation ensues from the following measure, leading to a III:PAC ( $\mathrm{A}^{\mathrm{b}}$ major). The form that $\mathrm{mm}$. 95-102 take is Caplin's hybrid 1 (antecedent +

18 After this cadence, the subordinate theme takes over. Thus the main theme fuses with the transition, a scenario that sometimes plays out within a recapitulation. Within this particular work, however, the same fusion also transpires within the exposition, an event that rarely occurs within a sonata-form movement. For more on this topic, see Caplin 1998, 165-67 and Hepokoski and Darcy 2006, 95.

19 Dotted lines in brackets outlining invertible zones, such as those at (a) and (b), indicate that at least one of the parts participating within the inversion has undergone slight changes; this method of indicating such changes within the invertible zone will be maintained throughout the article.

20 Although the boundary between the basic idea and contrasting idea is located midstream within a descending fifths sequence, the latter idea is distinguished from the former through the authentic cadence it articulates. Moreover, in some cases, a contrasting idea can sometimes borrow motivic ideas from the basic idea (as is done here), despite the nomenclature used to differentiate them. For more on this issue, see Caplin 1998, 49. 

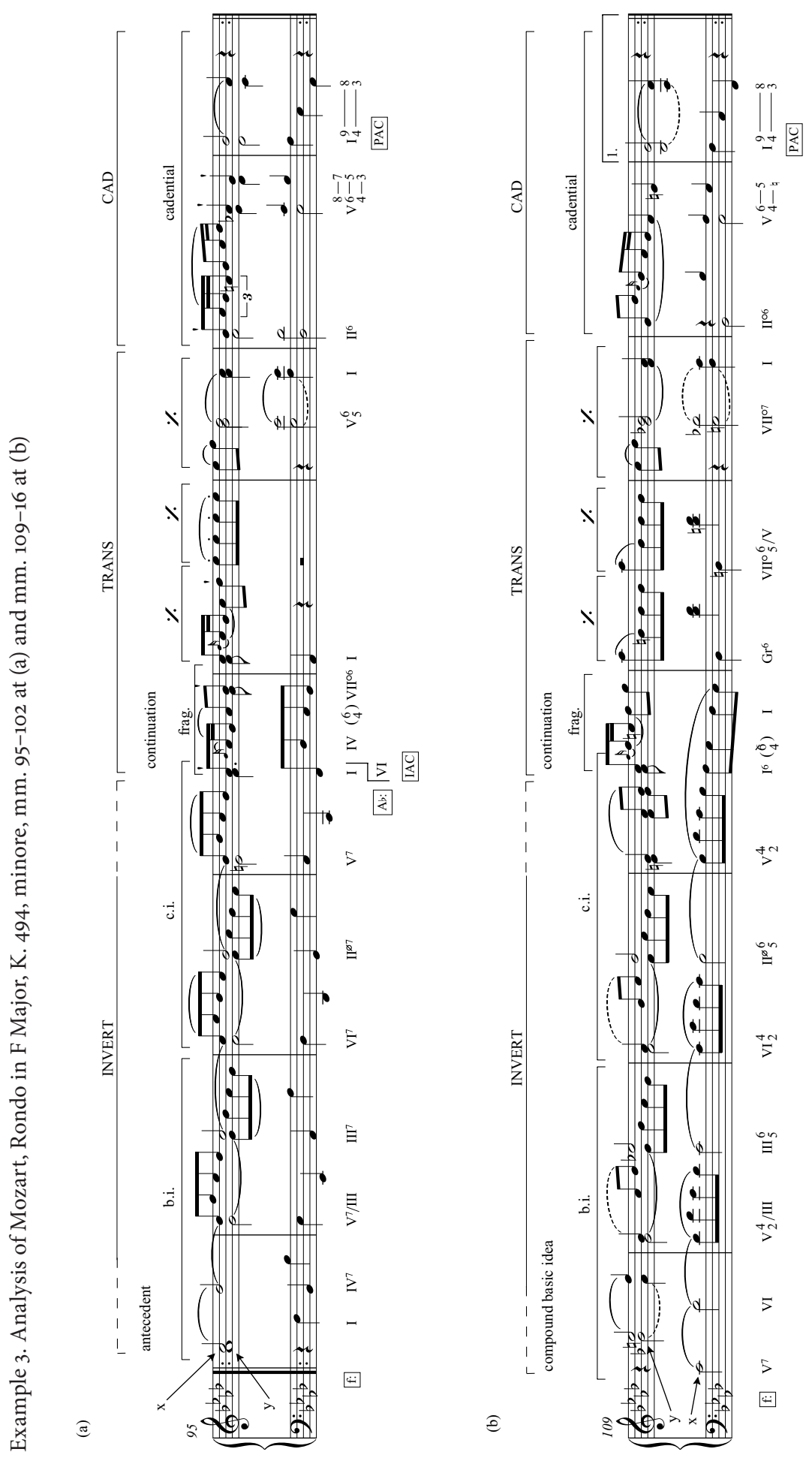
continuation). When this theme returns at the end of the minore, shown at (b), the inversion of $x$ with $y$ avoids cadential articulation and projects a formal function different from that shown earlier within the first four measures at (a). Now at (b), as a result of the presence of $x$ in the bass, what had been a cadence at the end of an antecedent becomes no cadence at the end of a compound basic idea; here the dominant-tonic motion in $\mathrm{m}$. 112 is substantially weakened by $\mathrm{V}_{2}^{4}$ resolving to $\mathrm{I}^{6}$. Such cadential avoidance postpones tonic cadential closure until the end of the theme. The delay of tonic confirmation here intensifies the conclusion of the binary form within which the theme participates, in a strategy that is further enhanced by the chromatically inflected bass line in m. 113. Additionally, intensity grows from the change in harmonic meaning that supports the theme at (b), most notably in its opening measure (m. 109), resulting from the inversion of $x$ with $y$. Since $x$ begins on 5 , placement of this scale degree into the bass as support for tonic harmony would be untenable. Thus Mozart changes the harmonic tack at this point by beginning the theme at (b) with dominant harmony, a bold move, given the half cadence in the preceding measure (not shown). Overall, the changes in form-functional and cadential design described here imbue the binary form in which these themes reside with heightened intensity, the result of which stems largely from the application of invertible counterpoint.

Avoiding monotony (as in example 2), delineating formal patterning, and evading cadential closure (as in the last example) are three primary reasons invertible counterpoint is employed in Beethoven's String Quartet in C Minor, op. 18/4, ii (example 4). Here, a twenty-five measure period (expanded from a sixteen-measure model wherein the antecedent phrase consists of a sentence [see table 1]), is shown. In the large-scale antecedent, parts $x$ and $y$ occur in violins I and II, respectively, and are presented in imitation; in the large-scale consequent, both parts invert with each other by occupying the viola and violin I, respectively, at least within the section leading up to the first attempt at cadential closure (mm. 51-61); part $x$ returns to violin I within a repeat of the continuation (mm. 61-67), whereas only a shadow of part $y$ moves to the cello. The invertible zone is clearly evident in the presentations of the large-scale antecedent and consequent. The continuations in both halves of the period, however, are slightly more complex, since there are three instances of them, not two, thus allowing more comparisons to be made regarding invertibility. When comparing the first two, no discernable content is shared; thus we can say that the second continuation triggers the onset of the transitional zone. But a case could be made for invertibility between the second two continuations, since they both contain parts $x$ and $y$, despite the weakened presence of the latter. ${ }^{21}$ I will first discuss the purpose of using invertible counterpoint within the two presentations, followed by a discussion of its use in the continuation and its repetition within the large-scale consequent.

21 Changes to part $y$, which produce such weakening, provide the rationale for using dotted brackets to outline the invertible zones here. 

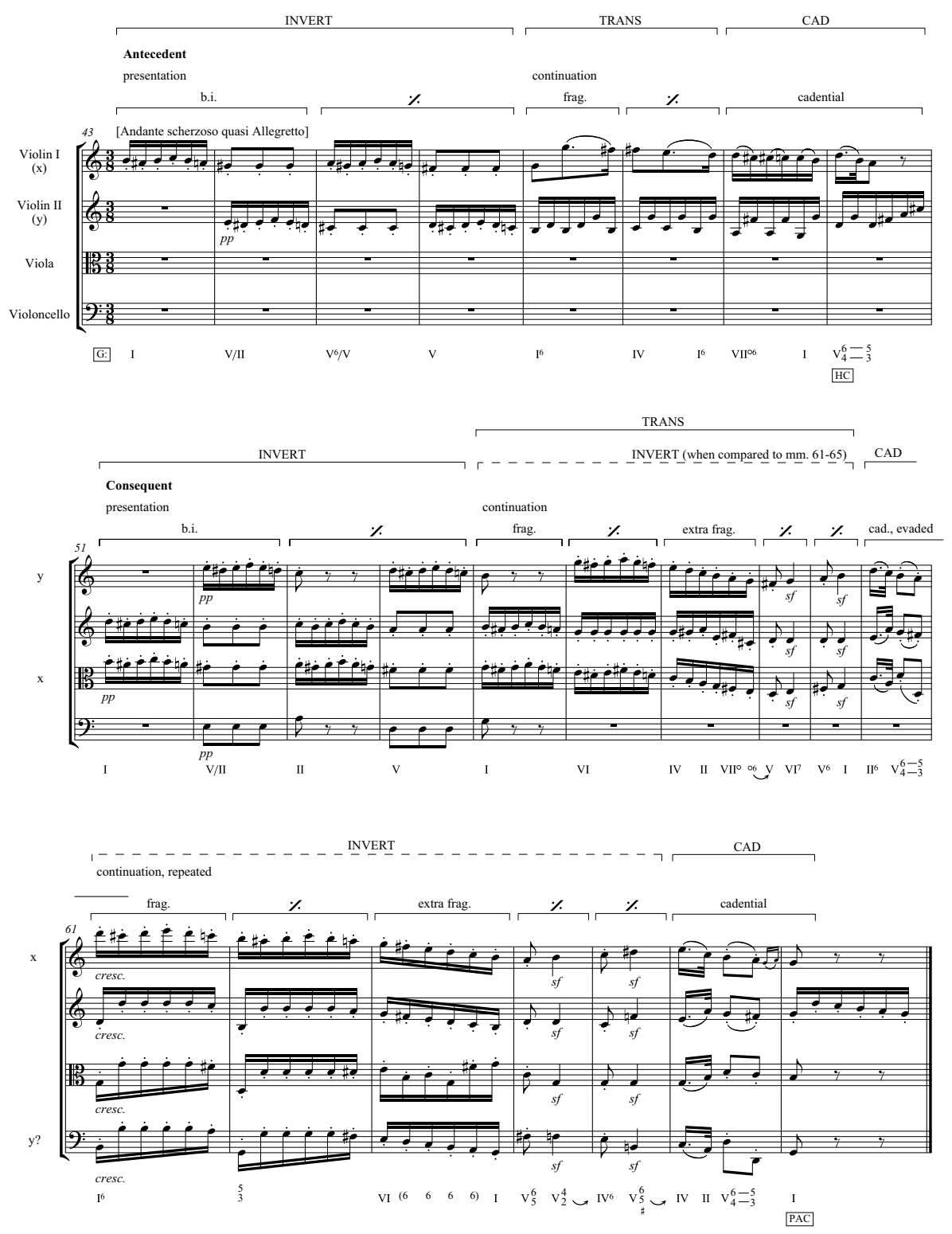

Example 4. Beethoven, String Quartet in C Minor, op. 18/4, ii, mm. 43-67

Since the motivic organization in both presentations is highly repetitivefour statements of the opening sixteenth-note motive occur in direct succession-introducing variety through invertible counterpoint becomes a welcome addition to the formal scheme. Beethoven achieves this in two ways. First, imitation integrates invertible counterpoint into the texture. In this vein, part $x$ begins with the aforementioned sixteenth-note motive and follows it with a repeated eighth-note motive; part $y$ imitates this pattern at the time-interval 
of one measure. The result of this imitation scheme is that both motives are inverted with each other, from one measure to the next. Second, inverting $x$ with $y$ provides further variety by texturally differentiating the consequent from the antecedent. Moreover, this differentiation helps to delineate the overall form of the theme.

In addition to providing variety, invertible counterpoint within the continuation provides a means of evading cadential closure within the consequent, and thus expanding the dimensions of the theme. As a result of the cadential evasion, the continuation undergoes a repetition ( $\mathrm{mm} .61-67)$, within which cadential closure is achieved. ${ }^{22}$ In the first continuation, the viola, carrying part $x$, begins a descent from $\mathrm{G}_{4}$ in $\mathrm{m}$. 55, first moving through descending thirds G-E-C (supporting the progression I-VI-IV), and then plummeting towards $\mathrm{D}_{3}$ in $\mathrm{m} .58$, supporting V. ${ }^{23}$ As a counterpoint, part $y$ in violin I moves with the viola's descending thirds in parallel tenths by way of the succession B$\mathrm{G}-\mathrm{E}$, ending up on $\mathrm{F}_{4} 4$ in $\mathrm{m}$. 58 . What follows are punchy, eighth- and quarternote fragments, leading into a cadential progression starting on $\mathrm{II}^{6}$ in $\mathrm{m} .60$. Cadential closure is evaded, however, largely as a result of the inversion of parts $x$ and $y$ in $\mathrm{m} .61$, signalling a repetition of the continuation. ${ }^{24}$ The major player in this evasion is part $y$, which now appears in the cello and begins by outlining descending thirds (B-G-E, supporting the progression $\left.\mathrm{I}^{6}-\mathrm{I}-\mathrm{VI}\right)$, a succession only hinted at by violin I within the previous continuation; part $x$, meanwhile, as stated by violin I, creates parallel tenths with the cello. (Part $x$ also expands the register to D6, a means of creating intensity.) Upon the arrival on $\mathrm{F}_{3}$ in $\mathrm{m} .64$, the cello deviates from the path that violin I had taken in the previous continuation and instead continues descending-part $x$ in violin I, however, continues to stay the course, and moves upwards-ultimately landing on $\mathrm{C}_{3}$ in m. 66 and sparking the onset of a second cadential progression, one that ends successfully on a V:PAC in $\mathrm{m}$. 67. The use of invertible counterpoint in the continuation thus does more than just provide textural variety; it also provides a technical means of evading cadential articulation and, therefore, expanding and intensifying the form.

Evasion of cadential articulation by invertible counterpoint becomes an overriding formal strategy within the first movement of Mozart's Piano Sonata in F Major, K. 533, i (example 5). At first blush, the motivic organization of the passage takes on a periodic guise, with two eight-measure sentences seemingly combining to form a large-scale period: what would be the large-scale antecedent features part $x$ over part $y$, followed by a large-scale consequent

22 Repeating the continuation in this manner is an instance of the "one more time" technique. For a discussion of applying this technique in combination with invertible counterpoint, see Schmalfeldt 2011, 48.

23 The beginning of this descent, G-F ition in the large-scale antecedent in violin I in $\mathrm{mm}$. 47-48 (where $\mathrm{FH}^{\#}$ substitutes for $\mathrm{F}^{\mathrm{b}}$ ). Additionally, this earlier passage features an arpeggiated figure starting on B in violin II (as contained within part $y$ ), corresponding to a single instance of the same pitch class in violin I in the analogous passage in $\mathrm{m}$. 55, thus projecting a slight trace of invertible counterpoint at the beginning of the transitional zone.

24 The inversion here results from applying invertible counterpoint at the twelfth, through which part $x$ is transposed up a twelfth and part $y$ down an octave. 

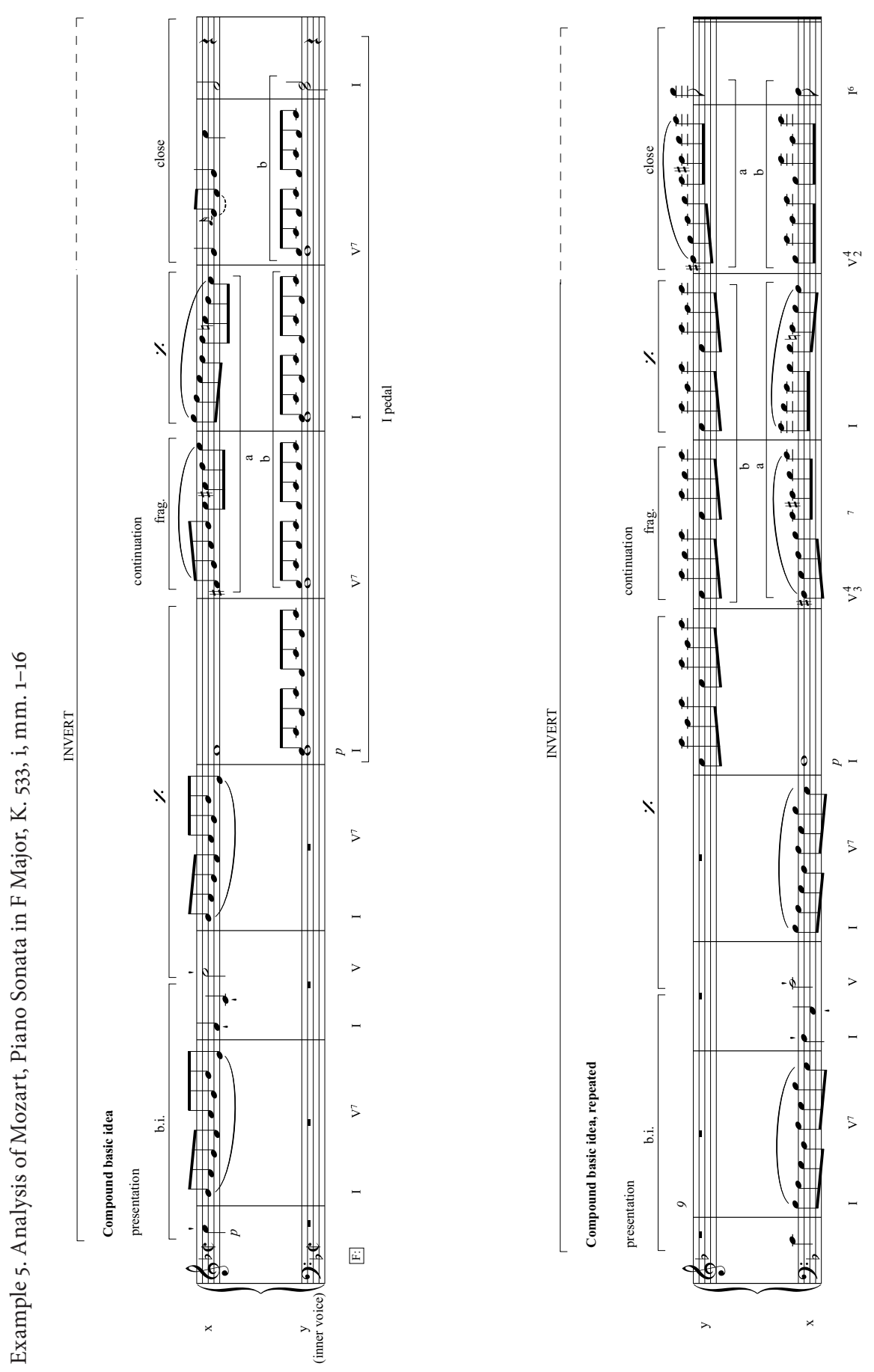
featuring an inversion of both parts. (The invertible zone comprises both halves of the passage shown here, albeit with some minor deviations toward the close of each, to be discussed.) Lack of cadential articulation, however, precludes such a reading-the tonic pedal sitting beneath the V7-I progression in $m m .7-8$ prevents an authentic cadence from sounding, as does the $\mathrm{V}_{2}^{4}-\mathrm{I}^{6}$ progression in the analogous position in $\mathrm{mm} .15-16$. Although these progressions do not support authentic cadences, they still provide means of closure, just not cadential. ${ }^{25}$ Thus, these progressions close off, not an antecedent and consequent phrase, but rather an expanded compound basic idea and its subsequent repetition, two formal functions that participate within a presentation of a large-scale sentence. ${ }^{26}$

What drives the large-scale sentential reading here is the dialogue between the right and left hands. ${ }^{27}$ Part $x$, which begins alone, takes on a primary role within the dialogue, whereas part $y$, as a result of its accompanimental status, takes on a secondary one. The colloquy between these two parts serves two purposes. First, it helps to demarcate form at multiple levels, wherein the opening reports of part $x$ within the small-scale presentation are answered by the arpeggiated figuration of part $y$, which initiates the continuation; additionally, the beginning solo statements of part $x$ clearly highlight the repetition scheme of the large-scale presentation consisting of both compound basic ideas: the first statement projects the opening gambit of the compound basic idea, whereas the second one, with its migration to the opposite hand and lower octave, signals that a varied repetition of the compound basic idea is commencing. Dialogue also plays into the dearth of cadential content within the large-scale presentation here. Although the tonic pedal at the close of the first compound idea does much of the heavy work of quashing cadential articulation, the switching between hands of two motives, labeled $a$ and $b$, serve the same purpose at the close of the second compound basic idea. Both motives first appear at the start of the first continuation, with $a$ sitting above $b$, the latter of which undergoes a repetition within the ensuing close. (In the analysis, the cadential function has been replaced with a close function, inspired by the practice followed in Richards 2011, 203-10). With the inversion of part $y$ over part $x$ in the second compound basic idea, motive $b$ now resides above motive $a$ at the start of the continuation. The following close, however, deviates from what occurs in the analogous position in the first compound basic idea; the second close simply swaps motives $a$ and $b(\mathrm{~mm} .15-16)$ between hands from their original position at the beginning of the continuation two bars previous. The result of this swap is such that motive $b$ pushes the seventh of the $\mathrm{V}$ chord into the bass, an action that suppresses cadential articulation, thus allowing further dialogue to take place throughout the rest of the theme (not shown). In sum, invertible counterpoint and the

25 In this regard, see Richards 2011, which advocates for a semi-closed sentence, which "lacks cadential function but achieves closure on V or I through the use of a cadence-like progression" (203).

26 Although Caplin states that compound basic ideas can be formed only through the articulation of a basic idea and contrasting idea lacking a concluding cadence (1998, 61), recent research by Mark Richards demonstrates that sentential structures can also play the role of a compound basic idea (2011, 210-12), as is the case in Mozart's sonata here.

27 Keefe (2005, 67-69) discusses the use of dialogue within this sonata. 
dialogue that it engenders serve not only to delineate form, but also to provide a means of expanding the form of the main theme, thus creating an open-ended conversation between motives, parts, hands, etc.

The use of invertible counterpoint shown here within the main theme of $\mathrm{K}$. 533 is in keeping with what Keefe describes as a "marked increase in dialogue" within Mozart's later compositional output, an aspect of design that brings this and other of his late sonatas "into close correspondence with the Viennese piano concertos" $(2005,69)$. The one concerto that according to Keefe (69) represents the pinnacle of applying such "dialogic organization" is the Piano Concerto in C Minor, K. 491, i. As one would expect, dialogue easily evinces itself throughout the frequent exchanges between the piano and orchestra, but this is not the only way that it does so. Indeed, dialogue here also involves colloquies between parts, not only performing forces, which can exchange registral positions with each other.

As shown in example 6, one particular dialogue within the concerto is conducted between the two main structural parts within the first tutti statement of the opening ritornello (mm. 1-112): the primary part as first stated in violin I and the upper winds $(x)$ and the accompanying descending part in the lower strings and winds $(y) .{ }^{28}$ Since the ritornello undergoes numerous repetitions throughout the movement, articulating dialogue via invertible counterpoint becomes one way of creating variety throughout. The focus here is on the front portion of the theme (mm. 13-22), which includes a compound basic idea followed by a sophisticated series of fragments that initiate the continuation, leading into the cadential function. (The theme itself in its entirety projects Caplin's hybrid 3 [compound basic idea + continuation].) The invertible zone begins right from the start: the tonic pedal within $y$ boldly asserts the $\mathrm{C}$ based tonality, whereas the arpeggiated ascent of $x$ dramatically sets forth the minor-mode basis of the movement. The continuation is characterized by the chromatic descent of $y$, as it charges downward towards $\mathrm{F}$ in eighth notes-an instance of the characteristic passus duriusculus pattern ${ }^{29}$ - and the gradually descending, undulating motion of $x$, which is punctuated by abrupt upward leaps of a sixth, also making its way towards $\mathrm{F}$ (supporting ${ }^{b} \mathrm{II}^{6}$ ), situated on the downbeat of $\mathrm{m}$. 22. Although part $x$ articulates the primary melodic content of this passage, part $y$, while not outwardly melodic, contributes to the relatively high level of chromaticism displayed here, elevating the topos of lament (and perhaps tragedy) that such descending bass lines often project. ${ }^{30}$

The same tack is taken between both parts near the close of the opening ritornello, but with parts $x$ and $y$ exchanging registral positions (example 7); $x$ now takes the lower position and $y$ the upper. Here, however, when $x$ and $y$ converge on F near the end of the end of the excerpt (m. 72), the harmony is $\mathrm{II}^{\circ}$, rather than the Neapolitan. Within both passages excerpted in examples

${ }^{28}$ Hepokoski and Darcy understand part $x$ as an idée fixe or motto of which its "regular resurfacings ... serve as threads binding together a highly varied discourse" $(2006,483)$.

29 According to Christoph Bernhard, such a pattern may rise or fall and is not necessarily relegated to the bass voice. See Hilse 1973, 103-04.

30 In this regard, see Rosand 1979. 

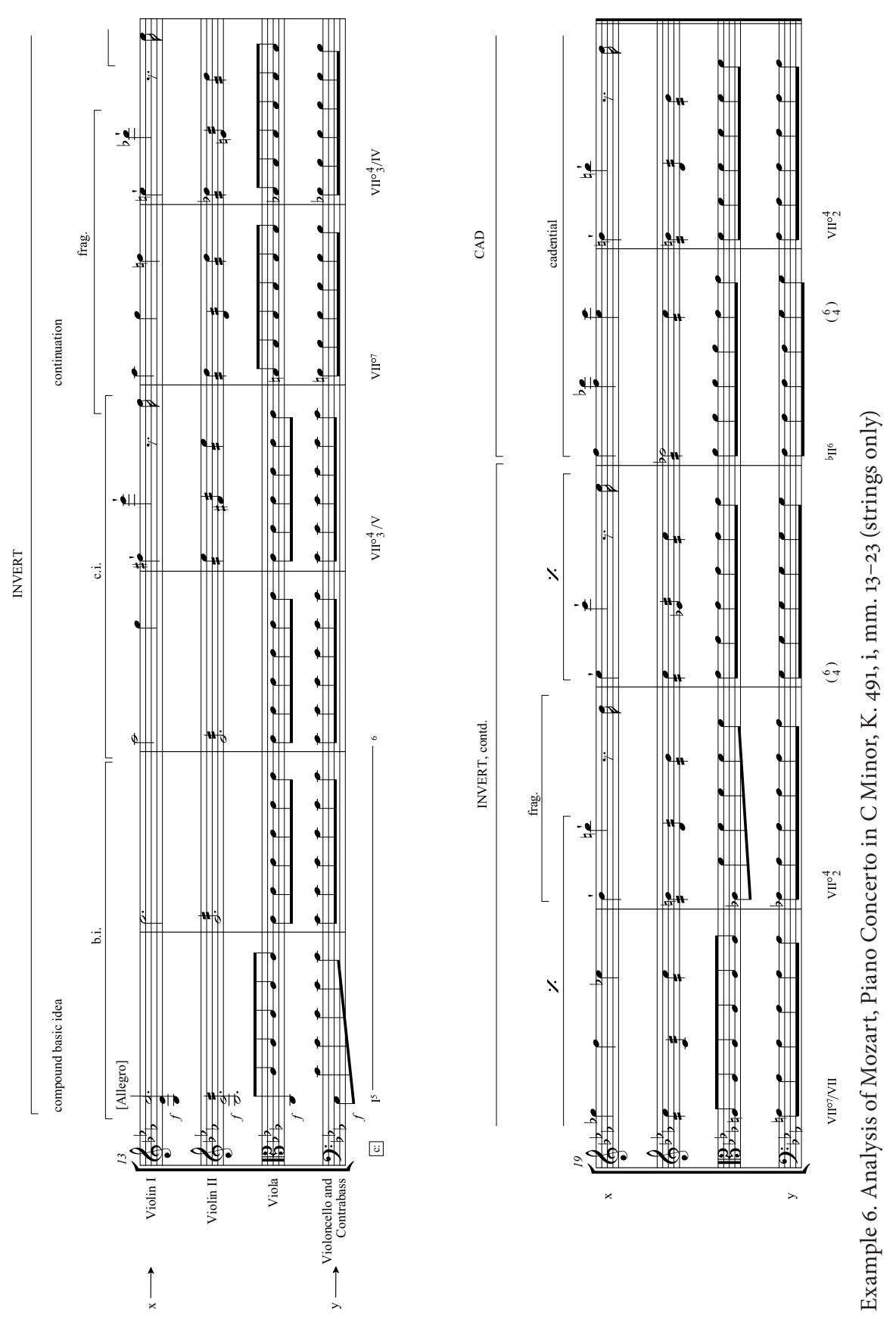


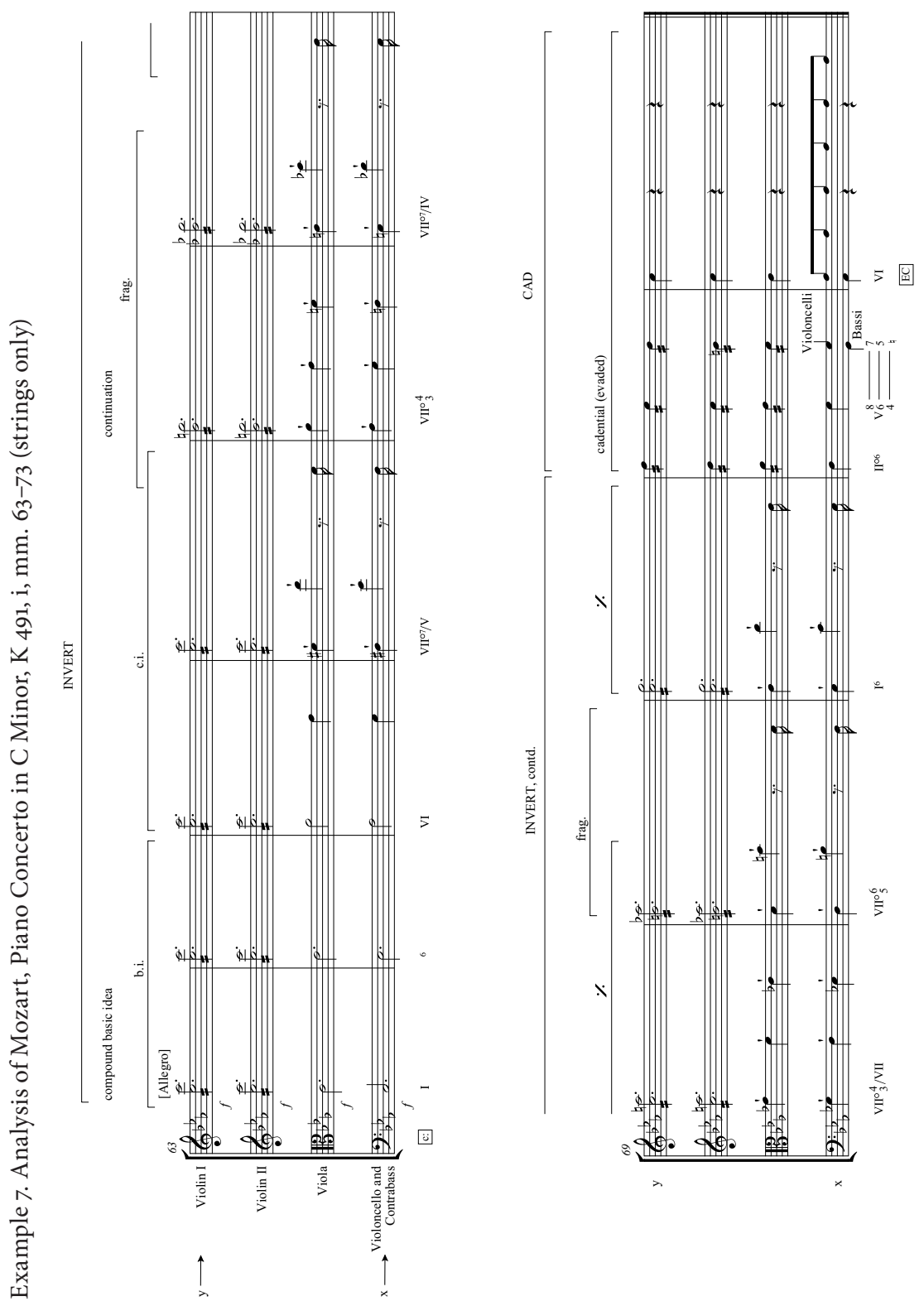

6 and 7 , the invertible zone ends just before the arrival of ${ }^{b} \mathrm{II}^{6}$ and $\mathrm{II}^{\circ 6}$, respectively, since after this arrival, the continuations of both passages diverge from each other (not shown): the former wends its way towards a i:HC and the latter a i:PAC (which eventually occurs after the deceptive move to VI in $\mathrm{m} .73$ ). 
Dialogue, therefore, does not occur only between the piano and orchestra of K. 491, but more abstractly between parts, which may reside in any instrument of the orchestra, as well as the piano. For instance, in example 6, part $y$ is featured in the lower strings and bassoon, whereas in example 7 it migrates up to violin I and oboe I. Of course, the formal structure of the theme contributes greatly to the orchestral shuffling that takes place between both dispositions of parts $x$ and $y$. As a result of the scarcity of cadences within both passages, parts $x$ and $y$ can appear within the upper or lower regions of the orchestra. Since the upward surge articulated by $x$ and the driving tonic pedal projected by $y$ reside within a compound basic idea, a formal function containing no cadence, both may occur in virtually any instrument of the orchestra. The same may said for the first part of the continuation, which presents a string of diminishedseventh chords in a descending-fifths sequence, another means of evading cadential articulation.

Thus, the dialogue between $x$ and $y$ that comes to the fore within the opening ritornello is enabled by the form that the theme takes, one that projects an amply sized invertible zone, devoid of cadential closure. This enabling of dialogue provides a method by which to showcase the instrumental forces of the orchestra and thus provide welcome variety through the subsequent repetitions of the ritornello.

Dialogue can also take place within the string quartet medium, as we have already seen in example 4; Beethoven's String Quartet in F Major, op. 18/1, i, provides another instance (example 8). Here the members of the quartet banter back and forth within the context of this sixteen-measure period, consisting of two hybrid 4 (compound basic idea + consequent) themes. Caplin, however, discourages such a formal scheme, "because the appearance of the basic idea to signal the lower-level consequent would poorly anticipate the higher-level consequent" $(1998,67)$. But the parallelism displayed within the large-scale antecedent and consequent strongly suggests that the basic idea appears twice within both phrases. And although the basic idea undergoes more repetitions than is expected according to Caplin's theory, the dialogue between different members of the quartet helps to demarcate the form of the theme at different levels of structure.

Specifically, the invertible zone corresponds to the compound basic ideas that occur at the beginnings of both halves of the sixteen-measure period; invertible counterpoint thus helps to delineate form at the sixteen-measure level. Within the large-scale antecedent, violin I begins alone with part $x$ as part of the basic idea, whereas the viola (which carries part $y$ ) and violin II enter the conversation with the onset of the contrasting idea. The parts then exchange positions within the large-scale consequent, where the cello now begins alone by stating part $x$, followed by the entry of violin I, carrying part $y$, along with the remaining strings. Although the two lower-level consequents reside outside the invertible zone, they still contribute to the conversation by allowing other members of the quartet to sound their voice: the viola, in the first consequent, and violin II, in the second. Thus, each statement of the basic idea is 

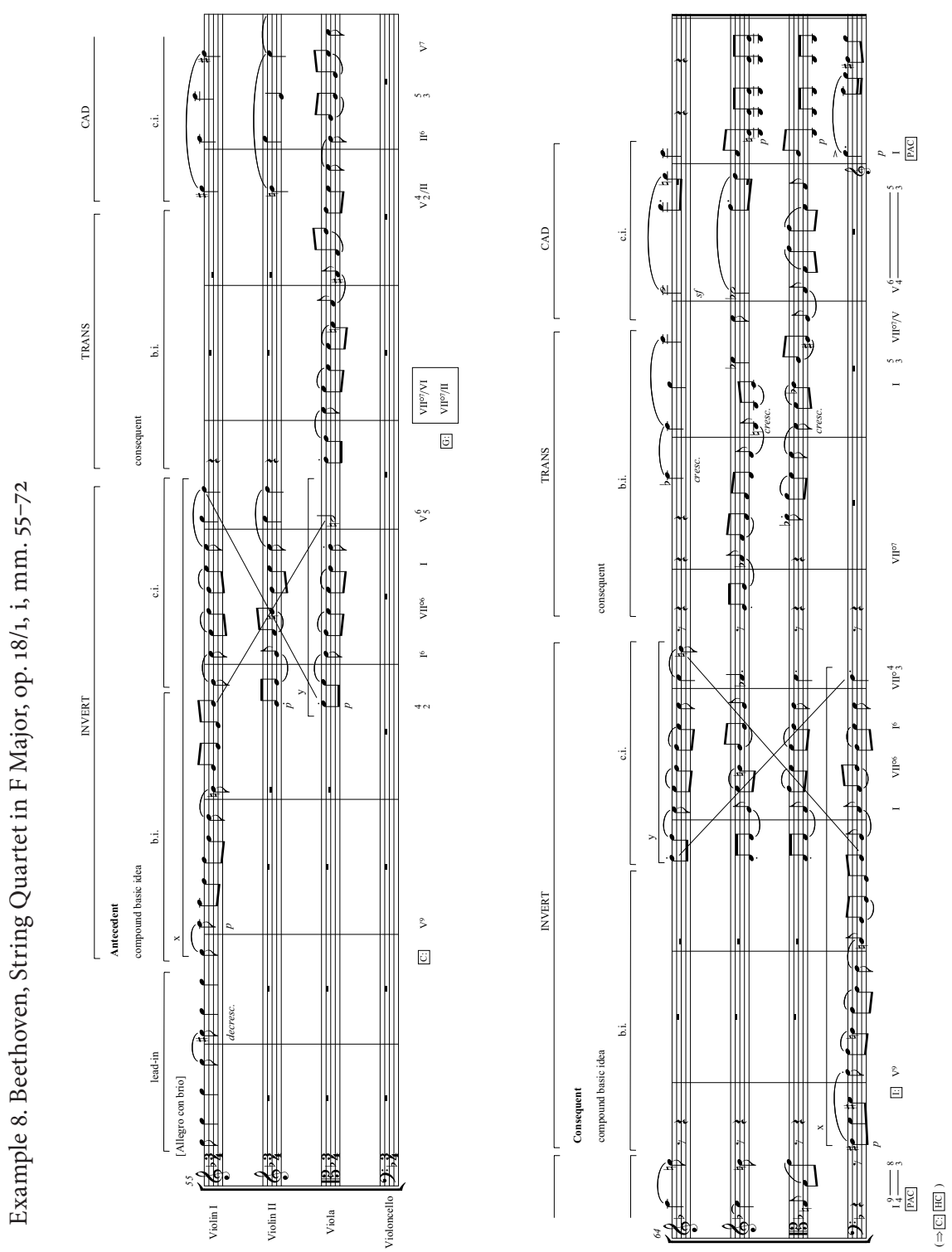

sounded by a different member of the quartet, each of whom texturally shapes the form of the theme.

Harmony and voice-leading are other factors that engage in this dialogue. In this sense, the inversion of parts $x$ and $y$ is enabled, partially, by the underlying harmony supporting both compound basic ideas, which feature B-F voice-exchanges that expand dominant harmony. These exchanges and the 

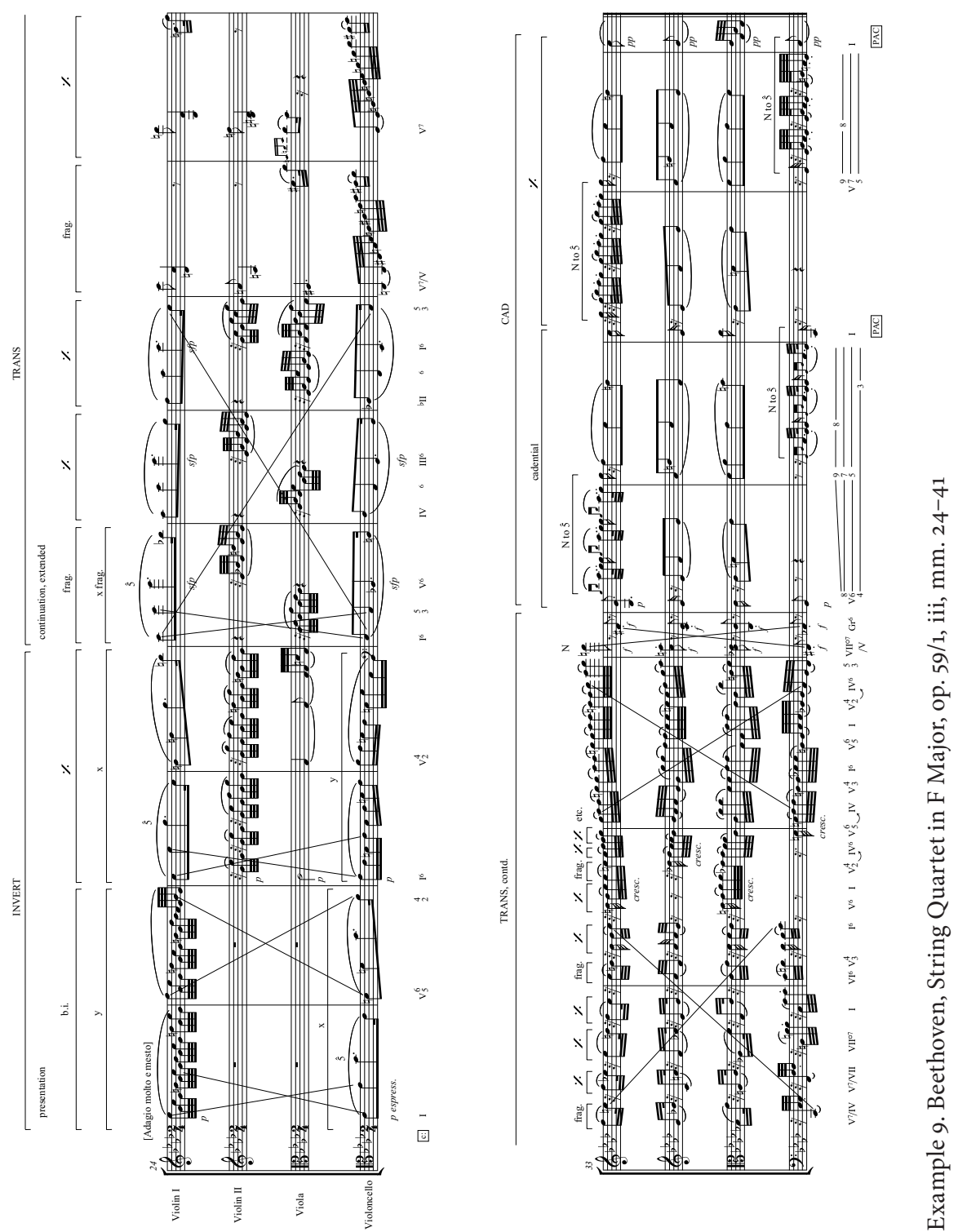

inversion of parts that they support also influence (or are influenced by) the form, since both compound basic ideas conclude with unstable harmonies precluding cadential articulation: $\mathrm{V}_{5}^{6}$ in the large-scale antecedent and $\mathrm{VII}_{3}^{\circ}$ in the large-scale consequent. ${ }^{31}$ What is more, the inversion of parts in the largescale consequent enables a registral connection within the bass voice: $F_{3}$ in $\mathrm{m}$. 68 connects to $\mathrm{F}_{3}$ in $\mathrm{m}$. 70 , en route to the structural dominant in $\mathrm{m}$. 71 . Thus,

31 The harmony concluding the compound basic idea within the large-scale antecedent could also be viewed as being $\mathrm{VII}^{\circ}$, but the analysis here takes into consideration the G-F succession in violin I, m. 6o, as being members of the prolonged dominant harmony. 
generally speaking, the form, underlying harmony, and voice-leading connections all work in concert with the dialogue taking place between the members of the quartet.

Similar dialogic organization obtains within Beethoven's String Quartet in F Major, op. 59/1, iii (example 9). The setting is the subordinate theme from this slow sonata-form movement. The theme itself is a sentence, with the invertible zone covering the presentation function. Here part $x$, an arpeggiation of tonic and dominant harmonies, is set against part $y$, a quicker-moving accompaniment featuring mostly stepwise motion (not counting the inner-voice pedal on $\mathrm{G}$ in violin I, later omitted when the cello states this part). The cello initiates the dialogue with part $x$, the primary part within the texture, while violin I nods in agreement by stating part $y$. This contrapuntal arrangement comprises the basic idea; both instruments then swap parts as part of the basic idea's repetition. As a result of the repetitive nature of the basic idea itself-in this sense, within part $x$, a motive supported by tonic harmony that is immediately repeated on the dominant-invertible counterpoint helps abate monotony. Following the presentation, the invertible zone closes, without there being further explicit articulations of invertible counterpoint. From this point forward, an extended continuation ensues (corresponding to the transitional zone), followed by a V:PAC in $\mathrm{m} .39$ and a repetition thereof in $\mathrm{m} .41$.

The dialogue between violin I and the cello, however, does not just entail the inversion of parts $x$ and $y$, it also evinces itself in different ways throughout the theme, expressing the rhetoric of invertible counterpoint, though more abstractly. For instance, numerous voice-exchanges occur between the outer voices (similar to those found in the previous example), such as between $\mathrm{C}-\mathrm{Eb}$ (mm. 24, 26, 28, and 28-30), $\mathrm{B}$ 4-F (m. 25) in the presentation, but also

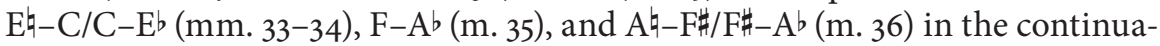
tion. The last exchange comes at a pivotal moment within the theme-violin I surges up to the highest pitch within the theme (A6) as the cello descends to $\mathrm{FH}_{2}$ - where the forte dynamic, chromaticism between the outer voices, and the diminished-seventh and augmented-sixth sonorities, all contribute to creating a considerable degree of tension. The tension, alas, dissipates in the following measure, with the arrival of the dominant, a lowering of the dynamic level to piano, the convergence of the outer voices on $\hat{5}$, a decrease in rhythmic surface activity, and the onset of the cadential zone. But although the tension abates, the conversation continues: violin I offers the chirping, neighbour-note figure to $\hat{5}$ in $\mathrm{m} .37$ and the cello responds in kind in the following measure, though making sure to round out the colloquy by resolving to root-position I in m. 39; the exchange is repeated in mm. 39-41, albeit with embellishments. Although the dialogue here consists of only a single part passed back and forth between both instruments, the rhetoric recounts the invertible situation at the beginning of the theme. Moreover, the focus on $\hat{5}$ also alludes to the opening of the theme, where part $x$ arpeggiates upward to it, first in the cello, and then in violin I, as parts $x$ and $y$ invert positions with each other; violin I elevates the emphasis on 5 further by repeating the tonic arpeggiation an octave higher and adorning it with a sforzando-piano dynamic at the onset of the continuation 

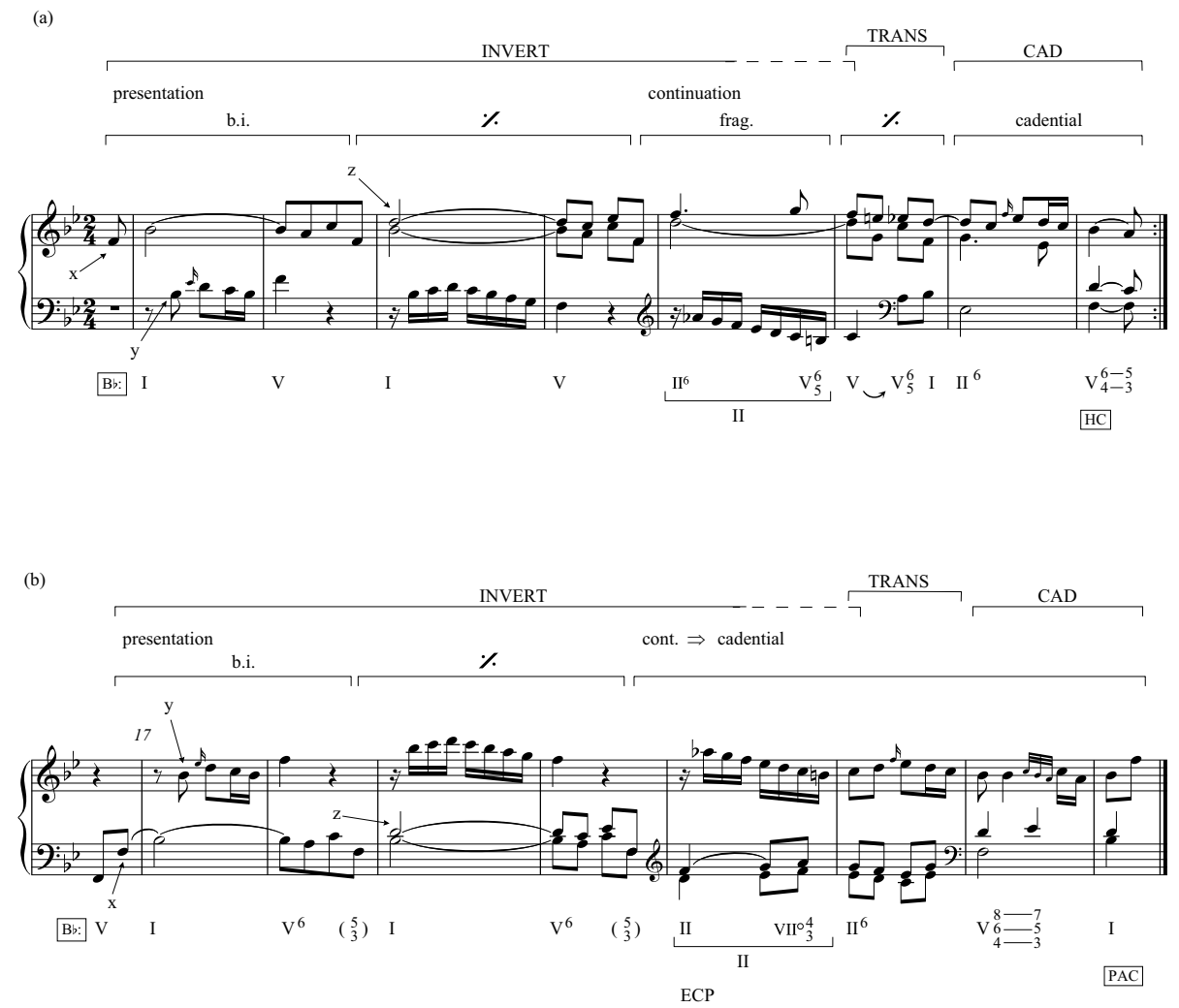

Example 10. Analysis of Haydn, Piano Sonata in $\mathrm{B}^{\mathrm{b}}$ Major, Hob. XVI:41, ii, mm. 1-8 at (a) and $\mathrm{mm} .17-24$ at (b)

in $\mathrm{m}$. 28. The register here, G6, is the same as that of the climax in $\mathrm{m} .36$, where A6 neighbours $\hat{5}$ in a highly dramatic fashion. Thus the dialogue throughout the theme does not evince itself only through the inversion of parts-a means of introducing variety-but also through voice-leading phenomena, such as voice-exchanges, which, in some cases, serve to highlight structural scale degrees, such as $\hat{5}$, in different registers and instruments.

\section{ANALYSES OF PIECES INVOLVING THREE OR MORE INVERTIBLE PARTS}

Three or more parts can also enter into an invertible relationship within the context of a theme, such as in Haydn's Piano Sonata in Bb Major, Hob. XVI:41, ii (example 10). ${ }^{32}$ Here we see two sentences taken from the theme (which is a rounded binary form) of this large-scale ternary movement. Three parts are at play within both sentences: $x$ and $y$, which are on a relatively equal footing

32 See Caplin 1998, 38-39, for an analysis of mm. 1-8, which is shown to illustrate exact repetition of the basic idea, albeit with melodic alterations. Use of invertible counterpoint is not mentioned. 
with each other, and $z$, which is essentially an upper-third doubling of $x$, thus fulfilling a secondary role. The three parts are arranged in the registral order $y, x, z$, as shown at (a);33 part $y$ moves up to the soprano in the second sentence, thus resulting in the registral order $x, z, y$, as shown at (b). The presentation contains only tonic and dominant harmonies: root position harmonies prevail at (a), whereas alternations between root-position and first-inversion harmonies occur at (b). The simple harmonic palette here partially contributes to the ease with which all three parts invert with each other.

In addition to creating variety, another reason for inverting these parts is to alter the functional content of the theme when it returns after the contrasting middle. The upshot is that the latter half of the theme now consists of the function continuation $\rightarrow$ cadential, rather than simply continuation; the change in function heightens the intensity level. Although the invertible zone within both themes comprises the presentation and only a fraction of the continuation, 34 the inversion at (b) sets up the drive to the home-key authentic cadence. Following this tack at (b), all three parts remain intact within the presentation, save for part $y$, which moves up an octave with the repetition of the basic idea, a register onto which it clings as it moves into the continuation. The acquisition of the higher register positions part $y$ amply well for the pending I:PAC, since it enables the sixteenth-note passage that starts on $A^{b_{5}}$ at the onset of the continuation to land on $\hat{2}$ in $\mathrm{m}$. 22, one step away from the $\hat{1}$ that appears (dissonantly) over the structural dominant in the following measure. Meanwhile, part $x$, which had been an inner voice at (a), now plays the bass role at (b), where it posits $\mathrm{D}_{4}$ at the beginning of the continuation. The structural bass line that ensues articulates the succession $\mathrm{D}-\mathrm{E}^{b}-\mathrm{F}-\mathrm{B}^{b}$ spread out over the final four measures, a succession that supports an expanded cadential progression (ECP), an integral component of the function continuation $\rightarrow$ cadential. Thus the modified continuation here, resulting from the application of invertible counterpoint, intensifies the drive to the home-key tonic at the conclusion of the binary form within which it resides.

The main theme from Haydn's Symphony in D Major, Hob. 104, i, also employs three invertible parts (example 11). The context here is the recapitulation, where the main theme takes the form of a sixteen-measure period made up of a hybrid 3 (compound basic idea + continuation) theme and a hybrid 1 (antecedent + continuation) theme. The texture of both halves of the period can be said to consist of a primary part $(x)$ and two secondary parts $(y$ and $z$ ). Part $x$ takes the highest register in the large-scale antecedent (violin I) and the lowest register in the large-scale consequent (oboe I). The main role of part $y$ is to double part $x$ in imperfect consonances, and that of part $z$ to provide a chain of 7-6 suspensions against the lowest part. Both parts $y$ and $z$ undergo slight

33 Throughout this article, any registral ordering of parts will always be from the bottom upwards.

34 For ease of reading, I use continuation here and throughout the rest of the paragraph as a catch-all for both continuation and continuation $\rightarrow$ cadential. 
INVERT
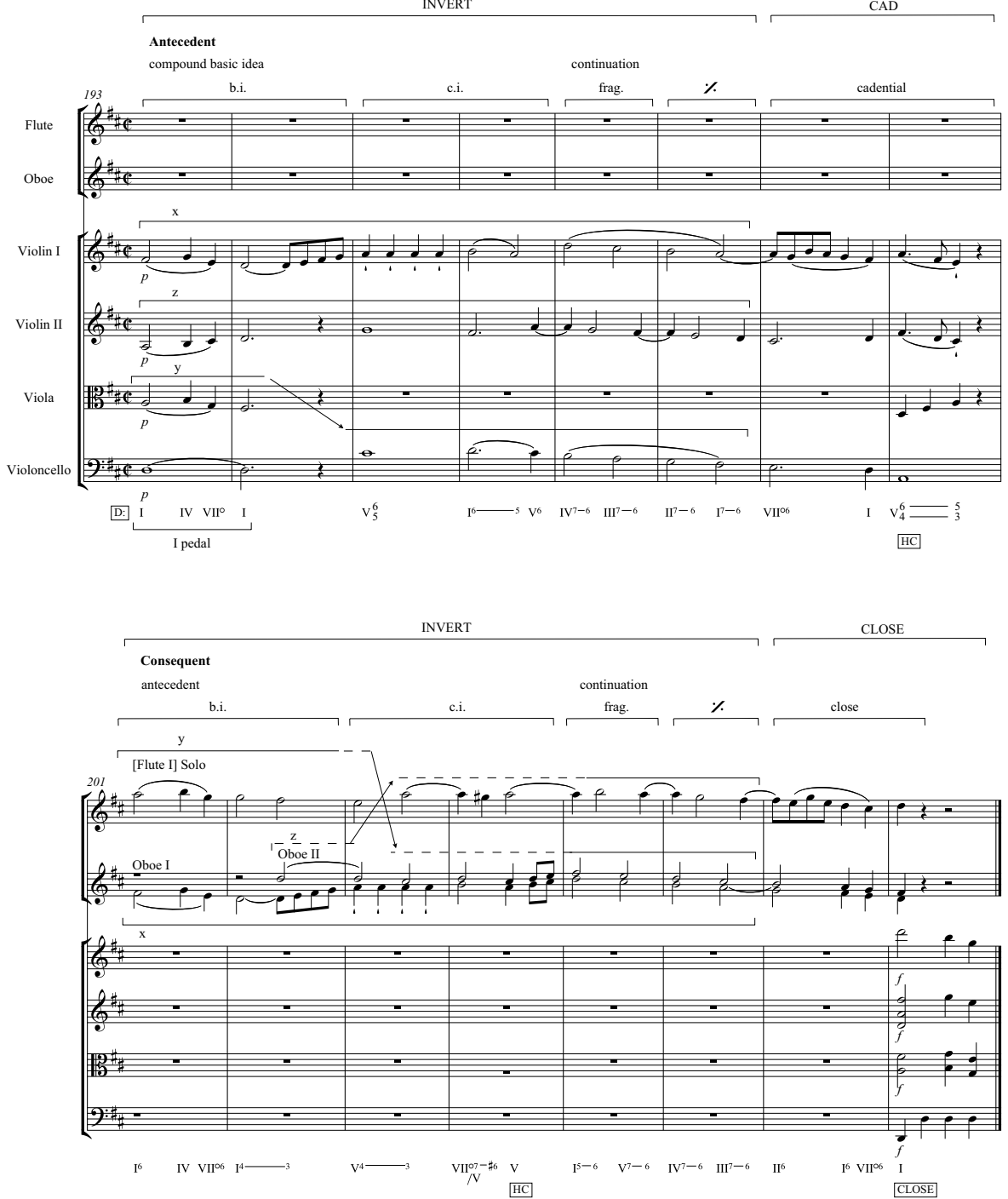

Example 11. Haydn, Symphony in D Major, Hob. 104, i, mm. 193-208 (the cadential zone is replaced with a close zone in the large-scale consequent)

changes in the large-scale consequent, though their main functions, just mentioned, remain intact throughout the entire theme. 35

The purpose of utilizing invertible counterpoint within the main theme is to provide variety, summon alternate formal functions, and modify cadential articulation. Variety, indeed, is an issue within this sonata-form movement, since it is monothematic. Such a thematic design threatens to create monotony,

35 The changes here are indicated with dotted lines above parts $y$ and $z$, only, not the invertible zone as a whole, since part $x$ remains completely intact, while parts $y$ and $z$ deviate somewhat. 
especially within the recapitulation, where the main and subordinate themes could potentially be indistinguishable because both are set in the home key. Thus the inversion of parts that takes place within the consequent-a tack that the impending subordinate theme does not follow-supplies sufficient contrast between the main and subordinate themes within the recapitulation.

The inversion of parts here also affects the formal and cadential scheme of the main theme. Within the large-scale antecedent, no cadence occurs within the contrasting idea, because of the $\mathrm{V}_{5}^{6}-\mathrm{I}$ progression; however, in the analogous place within the large-scale consequent, the multiple iterations of $\hat{5}$ in the bass voice, resulting from placing part $x$ into the lowest register of the texture, help to set up the half cadence that concludes the contrasting idea. (The alterations to parts $y$ and $z$ also facilitate the creation of this cadence.) The half cadence thus punctuates the end of a lower-level antecedent; moreover, it provides a formal contrast to what happens at the end of the large-scale consequent: a close supported by the progression $\mathrm{VII}^{\circ}{ }_{-} \mathrm{I}$, instead of the expected I:PAC, ${ }^{36}$ stemming mostly from the tight, third-doubling of part $y .37$ This reversal of closural strength within the large-scale consequent-a cadence followed by a close-postpones authentic cadential closure on the tonic until the end of the subordinate theme (in m. 267 , not shown), thereby heightening the overall intensity of the recapitulation.

Mozart involves four parts within an invertible context in his String Quartet in $\mathrm{Bb}$ Major, K. 458, iv (example 12). The theme here is within the subordinate-key area of the exposition and is based on a sixteen-measure period consisting of two sentences; the invertible zone comprises the presentations of both sentences, each of which features parts $w, x, y$ and $z$ in different registral arrangements (part $y$, though, never appears in the cello). Despite part $y$ 's reluctance to appear as the bass voice, each part is of relatively equal status, at least within the context here. (The motive in part $w$, however, is based on a fragment from the main theme, a situation that later challenges the general equilibrium expressed between the parts when this subordinate theme returns in the recapitulation.)

Variety becomes a pressing concern within the theme, because both presentations are highly repetitive. In this respect, all four parts participating within both presentations consist of two-measure motives that are iterated multiple times; a V-I progression supports each motivic statement. The iteration at play here involves what Hepokoski and Darcy call a "Mozartean loop" (2006, 80), a "short module ... that is either elided or flush-juxtaposed with a repetition of itself before moving forward into differing material." Here the loop corresponds to the basic idea, which undergoes two and a half iterations-the last

36 Richards 2010 examines how closural functions, instead of cadences, may be used to punctuate the ends of themes. The close here and the string of suspensions leading into it allude to the practice of species counterpoint (referencing the learned style), a practice that Haydn studied and within which such closes are standard fare. For Haydn's familiarity with Fuxian species counterpoint, see Mann 1973.

37 Were $x$ to move up to the root of the dominant in $\mathrm{m} .207, y$ would double the leading tone already present in the flute. 

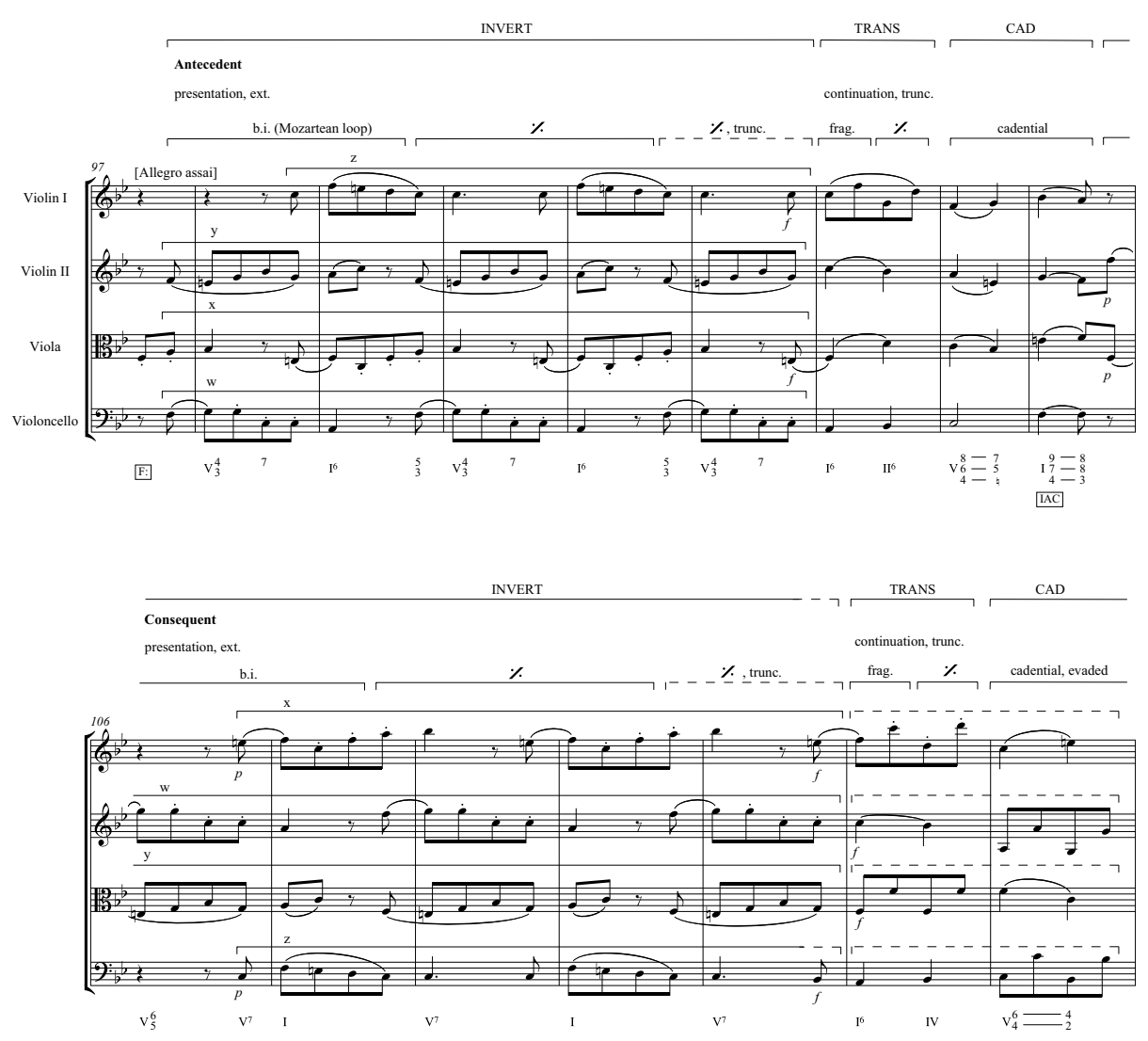

CAD, contd.

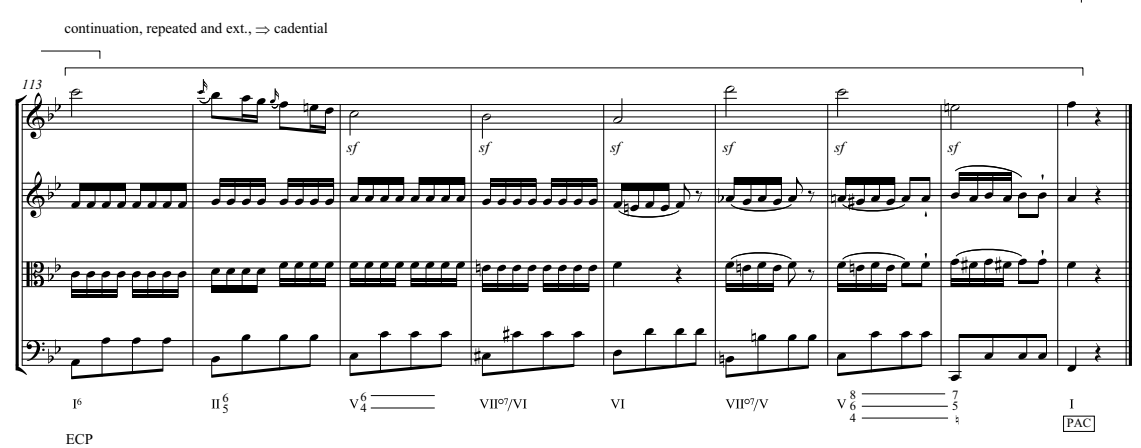

Example 12. Mozart, String Quartet in B ${ }^{b}$ Major, K. 458, iv, mm. 97-121

is shortened midstream and extends the presentation by one measure. With this repetition scheme, each part, at least within the invertible zone, projects a mechanical character, functioning as a cog within a contrapuntal clock that seemingly threatens to keep ticking away ad infinitum. As a way of ratcheting 

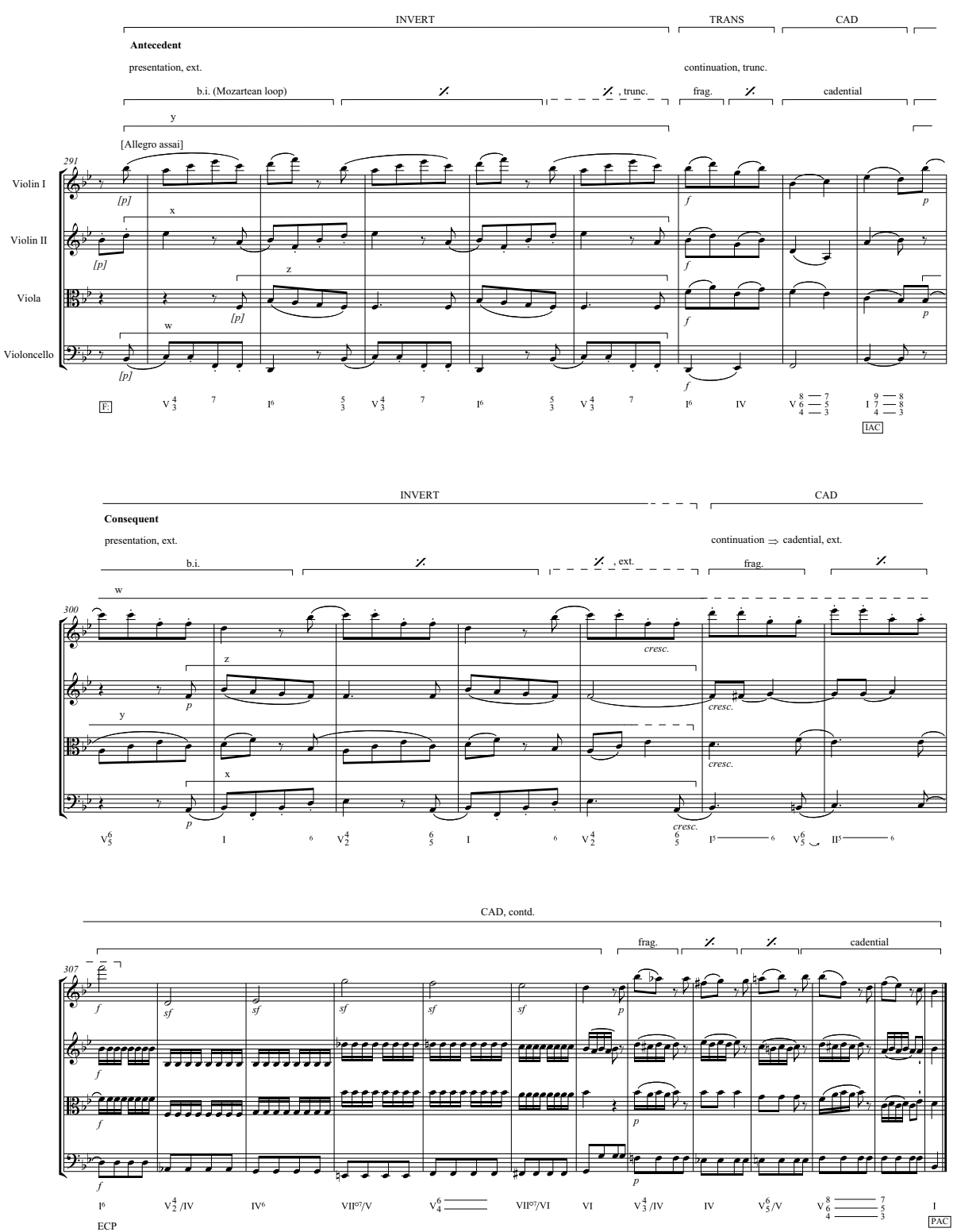

Example 13. Mozart, String Quartet in B ${ }^{b}$ Major, K. 458, iv, mm. 291-319

down this effect and averting monotony, the large-scale consequent refashions the inner workings of the presentation by registrally shuffling the four parts. Whereas the large-scale antecedent features parts $w, x, y$, and $z$, the large-scale consequent rearranges them as $z, y w$, and $x$. Thus what functions as the soprano ( $\operatorname{part} z$ ) in the former passage functions as the bass in the latter. Moreover, 
inverting parts in this manner provides welcome relief from the mechanistic repetitions within both presentations.

Relief also comes within the continuation phrases, wherein departures from the Mozartean loops occur. Within the large-scale antecedent, the exit from the loops leads to a V:IAC in m. 105. In the large-scale consequent, however, it involves an evaded cadence in $\mathrm{m}$. 113, pushing the bass down to $\hat{3}$; the arrival on the mediant in the bass at this point helps to launch an expanded cadential progression (ECP), which supports a repetition of the continuation and pushes towards a V:PAC in $\mathrm{m} .121$.

All four parts appear again, but in different registral order, with the return of this subordinate theme in the recapitulation (example 13). With the theme firmly planted in the home key, Mozart now rearranges the parts in the order $w, z, x, y$, in the large-scale antecedent. The large-scale consequent inverts parts again, with the parts arranged in the order $x, y, z$, and $w$. Whereas part $w$ had served only as a bass line and inner part within the exposition, now, within the large-scale consequent in the recapitulation, it takes the soprano role, thus highlighting the motivic fragment borrowed from the movement's main theme. The emphasis on this fragment becomes abundantly clear as part $w$ breaks out of the repetitive Mozartean loops that comprise the beginning of the presentation by sequencing the fragment upward through C6, D6, and Eb6, landing triumphantly upon F6 ( $(5)$ in $\mathrm{m}$. 307. The analogous position in the exposition also features a prominent 5 at the start of the continuation's repetition in the large-scale consequent (m. 113), though there it is approached through a rather awkward E45-C6 leap. The much smoother, but also more dramatic approach to $\hat{5}$ in the recapitulation demonstrates an ingenious coordination of motivic content and counterpoint, allowing part $w$ to rise to the top of the texture near the conclusion of the movement.

Part of this ingenuity stems not only from the invertible parts that Mozart was able to fashion together within both versions of this subordinate theme, but also the inversion scheme used to invert these parts. As shown in example 14(a), three basic transformations make up this scheme, resulting in the inversions that take place from the antecedent to the consequent of the theme within the exposition: (1) an upward shift of the two lower parts to become the two upper parts, (2) a downward shift of the highest part to become the lowest part, and (3), a downward shift of the alto to become the tenor. The entire scheme from the exposition is then flipped around a horizontal axis (represented by the dotted line) to become the scheme employed in the recapitulation, shown at (b). To be sure, the registral ordering of parts does not undergo this same axial rotation; however, a distinction is being made here between content (parts $w-z)$ and the scheme of transformations used to invert that content. With the scheme set in place, Mozart is free to arrange the four parts the best way he sees fit, plugging them into the scheme such that $w$ becomes the primary focus near the end of the recapitulation. More subtly, we may also associate the relationship between the schemes to that between the tonal areas corresponding to the exposition and recapitulation, thus creating a contrapuntal analogue to the tonal forces that shape the movement. Thus, not only does the inversion of 
parts create variety at the level of the theme, it also becomes a formal strategy that works at the level of the sonata form in which it occurs.

Exposition

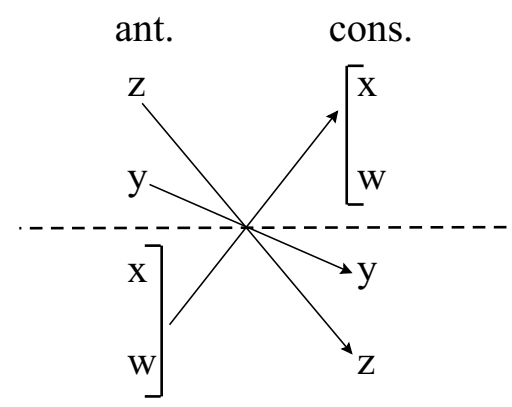

Recapitulation

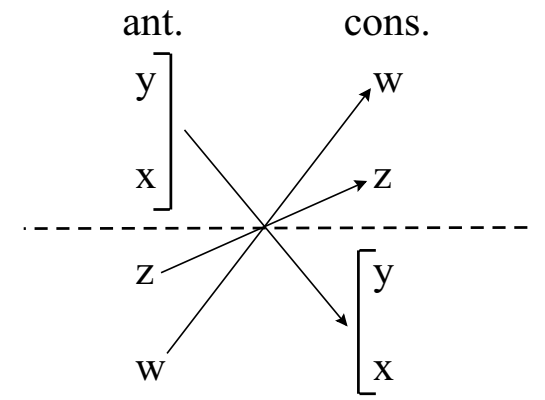

Example 14. Inversion scheme of subordinate theme in exposition and recapitulation in Mozart, String Quartet in B ${ }^{b}$ Major, K. 458, iv

\section{ConClusion}

Integrating invertible counterpoint into Classical-style works, as I have shown, does not fall only under the purview of fugal procedures. Indeed, the musical examples explored here have shown that it may reside within conventional theme-types that populate a variety of different forms, including sonata form and concerto form, and within works arranged for a variety of media, including solo piano, string quartet, and orchestra. Within such works, invertible counterpoint is applied to musical content that is repeated and divided texturally into distinguishable parts; in some cases, parts can play primary and secondary roles, and within others, they can be more evenly matched. Repetition of such musical content lies at the root of why invertible counterpoint is used. In this sense, invertible counterpoint provides a means to manipulate repetitions of musical content, the process of which can do the following: alter formal functions and cadential articulations; obscure boundaries between formal sections that share the same content; prevent monotony from prevailing within passages containing highly repetitive musical materials; help distinguish adjacent formal units that repeat musical content from one unit to the next; and expand formal sections, which can create space within which modulations can occur and/or contribute to generating intensity.

The basic model introduced within this essay aims to provide a simple framework with which to analyze such theme-types. Within this structure, the two primary zones-invertible and cadential_-provide a means of parsing out the musical surface into meaningful analytical spaces. The meaning gleaned from such analysis reveals that some theme-types are much more successful at incorporating invertible counterpoint than others, with the most successful being those with the fewest cadences. In other words, the sentence is the most 
amenable form for integrating invertible counterpoint, since it contains only one cadence; the period is less likely, since it contains two.

Integrating invertible counterpoint into theme-types also facilitates dialogue between parts, such as those articulated by opposite hands at the keyboard, the first violinist and cellist of a string quartet, or the winds and strings of an orchestra. Moreover, such dialogue enables invertible counterpoint to be not just a practical skill, but also a compositional technique used for building components of form, such as antecedents, consequents, presentations, etc. Thus, although some of the excerpts of invertible counterpoint surveyed within this essay do not match the complexity of, say, those found in J. S. Bach's Kunst der Fuge, they are often pressed into service more for their form-functional properties and less for their contrapuntal intricacy. The next stage of this study is to explore the extent to which invertible counterpoint pervades conventional theme-types within the Classical repertory.

\section{REFERENCES}

Agawu, V. Kofi. 1991. Playing with Signs: A Semiotic Interpretation of Classic Music. Princeton: Princeton University Press.

Allanbrook, W. J. 1983. Rhythmic Gesture in Mozart: Le Nozze di Figaro and Don Giovanni. Chicago: University of Chicago Press.

Balter, Tamara. 2012. "Parody of Learned Style." In Music Semiotics: A Network of Significations in Honour and Memory of Raymond Monelle, edited by Esti Sheinberg, 225-38. Burlington, VT: Ashgate.

Bey, Caroline, and Stephen McAdams. 2003. "Postrecognition of Interleaved Melodies as an Indirect Measure of Auditory Stream Formation." Journal of Experimental Psychology-Human Perception and Performance 29 (2): 267-79.

Bregman, Albert S. 1990. Auditory Scene Analysis: The Perceptual Organization of Sound. Cambridge, MA: MIT Press.

Brown, Peter A. 2003. 'Eighteenth-Century Traditions and Mozart's 'Jupiter' Symphony K.551." Journal of Musicology 20 (2): 157-95.

Cambouropoulos, Emilios. 2008. "Voice and Stream: Perceptual and Computational Modeling of Voice Separation." Music Perception 26 (1): 75-94.

Caplin, William E. 1998. Classical Form: A Theory of Formal Functions for the Instrumental Music of Haydn, Mozart, and Beethoven. New York: Oxford University Press.

_.2009. "Beethoven's Tempest Exposition: A Springboard for Form-Functional Considerations." In Beethoven's Tempest Sonata: Perspectives of Analysis and Performance, edited by Pieter Bergé, Jeroen D'hoe, and William E. Caplin, 88-125. Leuven: Peeters.

Cherubini, Luigi. 1854. A Treatise on Counterpoint \& Fugue. Translated by Mary Cowden Clarke; edited and revised by Joseph Bennett. London: Novello.

Deike, Susann, Birgit Gaschler-Markefski, André Brechmann, and Henning Scheich. 2004. "Auditory Stream Segregation Relying on Timbre Involves Left Auditory Cortex.” NeuroReport 15 (9): 1511-14. 
Deutsch, Diana. 2010. "Hearing Music in Ensembles." Physics Today 63 (2): $40-45$.

Gjerdingen, Robert O. 2007. Music in the Galant Style. New York: Oxford University Press.

Goetschius, Percy. 1910. Exercises in Elementary Counterpoint. New York: G. Schirmer.

Grier, James. 2010. "The Reinstatement of Polyphony in Musical Construction: Fugal Finales in Haydn's Op. 20 String Quartets." Journal of Musicology 27 (1): 55-83.

Hatten, Robert S. 1994. Musical Meaning in Beethoven: Markedness, Correlation, and Interpretation. Bloomington: Indiana University Press.

Hepokoski, James, and Warren Darcy. 2006. Sonata Theory: Norms, Types, and Deformations in the Late-Eighteenth-Century Sonata. New York: Oxford University Press.

Hilse, Walter. 1973. "The Treatises of Christoph Bernhard." Music Forum 3:1-196.

Horton, Julian. 2006. "The Symphonic Fugal Finale from Mozart to Bruckner." Dutch Journal of Music Theory / Tijdschrift voor Muziektheorie 11 (3): $230-46$.

Huron, David. 2006. Sweet Anticipation: Music and the Psychology of Expectation. Cambridge, MA: MIT Press.

Keefe, Simon P. 2005. "Mozart's Late Piano Sonatas (K457, 533, 545, 570, 576): Aesthetic and Stylistic Parallels with His Piano Concertos." In Words about Mozart: Essays in Honour of Stanley Sadie, edited by Dorothea Link and Judith Nagley, 59-75. Woodbridge: Boydell.

Kennan, Kent. 1999. Counterpoint: Based on Eighteenth-Century Practice. 4th ed. Upper Saddle River, NJ: Prentice Hall.

Kirkendale, Warren. 1979. Fugue and Fugato in Rococo and Classical Chamber Music. 2nd ed. Translated by Warren Kirkendale and Margaret Bent. Durham, NC: Duke University Press.

Koch, Heinrich Christoph. 1983. Introductory Essay on Composition: The Mechanical Rules of Melody, Sections 3 and 4. Translated by Nancy Kovaleff Baker. New Haven, CT: Yale University Press.

Kollmann, Augustus Frederic Christopher. 1799. An Essay on Practical Musical Composition. Edited by Imogene Horsley. New York: Da Capo, 1973.

Mann, Alfred. 1973. "Haydn's Elementarbuch: A Document of Classic Counterpoint Instruction." Music Forum 3:197-237.

Meyer, Leonard B. 1973. Explaining Music: Essays and Explorations. Berkeley: University of California Press.

Monelle, Raymond. 2006. The Musical Topic: Hunt, Military, and Pastoral. Bloomington: Indiana University Press.

Pressnitzer, Daniel, Clara Suied, and Shihab A. Shamma. 2011. "Auditory Scene Analysis: The Sweet Music of Ambiguity." Frontiers in Human Neuroscience 5:1-11.

Prout, Ebenezer. 1891. Double Counterpoint and Canon. London: Augener. 
Ratner, Leonard G. 1980. Classic Music: Expression, Form, and Style. New York: Schirmer Books.

Richards, Mark. 2010. "Closure in Classical Themes: The Role of Melody and Texture in Cadences, Closural Function, and the Separated Cadence." Intersections: Canadian Journal of Music 31 (1): 25-45.

-2011. "Viennese Classicism and the Sentential Idea: Broadening the Sentence Paradigm." Theory and Practice 36:179-224.

Rosand, Ellen. 1979. "The Descending Tetrachord: An Emblem of Lament." Musical Quarterly 65:346-59.

Schmalfeldt, Janet. 2011. In the Process of Becoming: Analytic and Philosophical Perspectives on Form in Early Nineteenth-Century Music. New York: Oxford University Press.

Sisman, Elaine R. 1996. "Learned Style and the Rhetoric of the Sublime in the 'Jupiter' Symphony." In Wolfgang Amadè Mozart: Essays in His Life and His Music, edited by Stanley Sadie, 213-38. Oxford: Oxford University Press.

Somfai, László, 1986. "'Learned Style' in Two Late String Quartet Movements of Haydn.” Studia Musicologica Academiae Scientiarum Hungaricae 28 (1-4): $325-49$.

Somfai, László, and Agnès Ausser. 1988. “Le 'style savant' de Haydn: Les Stratégies Thématiques dans le Quatuor 'Les Quintes."” Analyse Musicale 13:51-57. Webster, James. 1991. Haydn's "Farewell" Symphony and the Idea of Classical Style: Through-Composition and Cyclic Integration in His Instrumental Music. Cambridge: Cambridge University Press.

\begin{abstract}
This essay investigates the use of invertible counterpoint within conventional themetypes encountered within Classical-style works. Whereas recent research has focused on how this contrapuntal technique provides a means of creating continuity, this article expands the purview by elucidating how it works in concert with theme-types, forms regulated by cadences (devices that arguably suppress continuity). A basic model provides the theoretical framework with which to analyze excerpts from a selection of works by Beethoven, Haydn, and Mozart. The analyses reveal that some theme-types are more successful than others at integrating invertible counterpoint into their formal design. Moreover, the analyses uncover the purpose of using invertible counterpoint within theme-types.
\end{abstract}

\title{
RÉSUMÉ
}

Cet article examine l'utilisation du contrepoint réversible dans le cadre d'œuvres thématiques conventionnelles de la tradition classique. Alors que de récentes recherches ont étudié comment cette technique contrapuntique peut créer une continuité, cet article contribue à cette question en montrant comment cette technique fonctionne de concert avec l'écriture thématique et les formes organisées par les cadences, et qui ont le propre d'interrompre la continuité. Un modèle de base sert de cadre théorique permettant l'analyse d'extraits tirés d'une sélection d'œuvres de Haydn, Mozart et 
Beethoven. Les analyses montrent que certains types d'écriture thématique intègrent mieux que d'autres l'utilisation du contrepoint réversible dans leur organisation formelle. De plus, ces analyses mettent en lumière les divers rôles du contrepoint inversé dans les différentes formes thématiques. 